\title{
(Q) Advancing research diagnostic criteria for Alzheimer's disease: the IWG-2 criteria
}

\author{
Bruno Dubois, Howard H Feldman, Claudia Jacova, Harald Hampel, José Luis Molinuevo, Kaj Blennow, Steven T DeKosky, Serge Gauthier, \\ Dennis Selkoe, Randall Bateman, Stefano Cappa, Sebastian Crutch, Sebastiaan Engelborghs, Giovanni B Frisoni, Nick C Fox, Douglas Galasko, \\ Marie-Odile Habert, Gregory A Jicha, Agneta Nordberg, Florence Pasquier, Gil Rabinovici, Philippe Robert, Christopher Rowe, Stephen Salloway, \\ Marie Sarazin, Stéphane Epelbaum, Leonardo C de Souza, Bruno Vellas, Pieter J Visser, Lon Schneider, Yaakov Stern, Philip Scheltens, \\ Jeffrey L Cummings
}

Lancet Neurol 2014; 13: 614-29 See Comment page 532 Centre des Maladies Cognitives et Comportementales, Institut du Cerveau et de la Moelle épinière, Paris, France (Prof B Dubois MD, Prof H Hampel MD, SEpelbaum MD, LC de Souza MD); Université Pierre et Marie Curie-Paris 6, AP-HP, Hôpital de la Salpêtrière, Paris, France (B Dubois, H Hampel,

S Epelbaum, L ( de Souza); Division of Neurology, University of British Columbia and Vancouver Coastal Health, Vancouver, BC, Canada (Prof H H Feldman MD); UBC Division of Neurology, S152 UBC Hospital, BC, Canada (C Jacova PhD); Alzheimer's

Disease and Other Cognitive Disorders Unit, Neurology Service, IDIBAPS Hospital Clinici Universitari, Barcelona, Spain (J L Molinuevo MD); BarcelonaBeta Brain Research Centre, Fundació Pasqual Maragall, Barcelona, Spain (J L Molinuevo); Clinical Neurochemistry Laboratory, Institute of Neuroscience and Physiology, Department of Psychiatry and Neurochemistry, The Sahlgrenska Academy at University of Gothenburg,

Sahlgrenska University Hospital, Mölndal, Sweden (K Blennow MD); Department of Neurology, University of Virginia, Charlottesville, VA, USA (Prof ST DeKosky MD); McGill Center for Studies in

Aging, Douglas Hospital, Montreal, Quebec, QC, Canada

(Prof S Gauthier MD); Harvard Medical School Center for Neurologic Diseases, Brigham and Women's Hospital, Boston,

MA, USA (Prof D Selkoe MD);

Washington University School of Medicine, St Louis, Missouri, MO, USA (R Bateman MD); Vita-Salute San Raffaele University, Milan, Italy

In the past 8 years, both the International Working Group (IWG) and the US National Institute on Aging-Alzheimer's Association have contributed criteria for the diagnosis of Alzheimer's disease (AD) that better define clinical phenotypes and integrate biomarkers into the diagnostic process, covering the full staging of the disease. This Position Paper considers the strengths and limitations of the IWG research diagnostic criteria and proposes advances to improve the diagnostic framework. On the basis of these refinements, the diagnosis of AD can be simplified, requiring the presence of an appropriate clinical AD phenotype (typical or atypical) and a pathophysiological biomarker consistent with the presence of Alzheimer's pathology. We propose that downstream topographical biomarkers of the disease, such as volumetric MRI and fluorodeoxyglucose PET, might better serve in the measurement and monitoring of the course of disease. This paper also elaborates on the specific diagnostic criteria for atypical forms of $\mathrm{AD}$, for mixed $\mathrm{AD}$, and for the preclinical states of $\mathrm{AD}$.

\section{Introduction}

In 2007, the International Working Group (IWG) for New Research Criteria for the Diagnosis of Alzheimer's Disease (AD) provided a new conceptual framework that proposes to anchor the diagnosis of $\mathrm{AD}$ on the presence of biomarkers. ${ }^{1}$ A goal of these diagnostic criteria, and of the subsequent National Institute on Aging-Alzheimer's Association (NIA-AA) criteria, ${ }^{2}$ has been to expand coverage of the full range of disease stages, from the asymptomatic through the most severe stages of dementia Potentially, their most important practical application is to allow earlier intervention in the prodromal stages of the disease and to facilitate research studies into secondary prevention of $\mathrm{AD}$ in the preclinical states. As we learn more through the research application of these criteria common ground is being found for the eventual development of a universal set of criteria that truly captures the essence of AD.

In parallel, research into biomarkers has helped to clarify the potential value of each marker in the diagnosis of AD. Data highlight the value of cued recall measures for the assessment of episodic memory impairment; the relevance of atrophy of the hippocampus and related structures has been revisited; the value, relation with pathology, and significance of CSF biomarkers are better known; and interpretation of data from amyloid PET imaging has improved, its correlation with pathology clarified, and new ligands have been introduced. The objectives of the proposed revision are to clarify, in the context of this consensus framework, how the criteria can be applied, maintaining the principle of a high specificity. Our aims are as follows: (1) to present a new diagnostic algorithm for typical AD; (2) to advance the diagnostic criteria for atypical AD; (3) to refine the diagnostic criteria for mixed $\mathrm{AD}$; (4) to elaborate the criteria for the diagnosis of the preclinical states of $A D$; and (5) to differentiate the biomarkers of AD diagnosis from those of AD progression.

\section{Conceptual advances of the new criteria}

AD has traditionally been defined as a type of dementia, a notion brought into existence with the publication of criteria from the National Institute of Neurological and Communicative Disorders and Stroke-Alzheimer's Disease and Related Disorders Association (NINCDSADRDA) in 1984. ${ }^{3}$ Two major tenets of these criteria were as follows: (1) the clinical diagnosis of AD could only be designated as "probable" while the patient was alive and could not be made definitively until Alzheimer's pathology had been confirmed post mortem; and (2) the clinical diagnosis of $\mathrm{AD}$ could be assigned only when the disease had advanced to the point of causing significant functional disability and met the threshold criterion of dementia. The absence at that time of clinical criteria for the other dementias and the lack of biomarkers resulted in a low specificity in differentiation of AD from other dementias. In 2007, the IWG for New Research Criteria for the Diagnosis of AD provided a new conceptual framework that moved AD from a clinicopathological to a clinicobiological entity. ${ }^{5}$ These 2007 IWG criteria proposed that $A D$ could be recognised in vivo and independently of dementia, in the presence of two requisite features. The first was a core clinical phenotypic criterion that required evidence of a specific episodic memory profile characterised by a low free recall that is not normalised by cueing. ${ }^{5}$ This memory profile differs from that observed in patients with non-AD disorders, such as frontotemporal dementias, progressive supranuclear palsy, Huntington's disease, major depression, or even normal ageing, in which the frontalrelated retrieval deficit is normalised by the cueing procedure. ${ }^{6-9}$ This pattern was secondarily shown to 
correlate significantly with hippocampal volume and, more precisely, with the CA1 field in three-dimensional hippocampal surface-based shape analysis. ${ }^{10}$ It was included as a core criterion because no other cognitive changes in "typical AD", whether at a prodromal (predementia) or dementia stage, are as specific to the disease. The second criterion was the presence of biomarker evidence consistent with and supportive of AD on: (1) structural MRI; (2) molecular neuroimaging with PET $\left({ }^{18} \mathrm{~F}\right.$-2-fluoro-2-deoxy-D-glucose PET [FDG PET] or ${ }^{11} \mathrm{C}$-labelled Pittsburgh compound B PET [PiB PET]); or (3) CSF analysis of amyloid $\beta(A \beta)$ or tau protein (total tau [T-tau] and phosphorylated tau [P-tau]) concentrations. The most innovative aspect of the 2007 criteria was the first introduction of biomarkers into the core diagnostic framework. This change enabled AD diagnosis to be extended into the prodromal stage, where the disease can be diagnosed with supportive biomarkers. The ambiguous nature of any categorical boundary between prodromal $\mathrm{AD}$ and $\mathrm{AD}$ dementia argues in favour of a unified and dimensional diagnostic approach that uses the same criteria for diagnosis irrespective of the severity of cognitive and functional deficits. The recognition of prodromal $\mathrm{AD}$ was an important advance over the broader and more heterogeneous state of mild cognitive impairment (MCI). Furthermore, the IWG diagnostic criteria served to disconnect the clinicobiological diagnosis of $\mathrm{AD}$ from the diagnostic requirement of having dementia and functional disability that impairs everyday life. The framework offered a single set of criteria that were applicable at all clinical stages of disease across the entire disease continuum. Their main limitations were the focus on only typical $\mathrm{AD}$ with amnestic presentations and the absence of ordering or weighting of the supportive biomarkers.

The first important refinements to the 2007 criteria were made by the IWG in 2010. ${ }^{11}$ A lexicon was proposed that clearly drew a distinction between the clinical disease (AD) and disease pathology (Alzheimer's pathology)which is defined by specific neuronal lesions observed post mortem, including senile plaques and neurofibrillary tangles associated with neuronal loss, synaptic loss, and frequently with cerebral amyloid angiopathy-because this pathological process might not have been symptomatic during life. In turn, this distinction broadened the spectrum of the disease to include its preclinical states, in which Alzheimer's pathology exists without clinical symptoms. Two states were proposed for preclinical AD: "asymptomatic at-risk state for $\mathrm{AD}$ " and "presymptomatic AD". The former group includes individuals with biomarkers of Alzheimer's pathology but without clinical symptoms or signs. These individuals are classified as being asymptomatic at risk of $\mathrm{AD}$ because the percentage of individuals with positive biomarkers who will progress to symptomatic clinical conditions is not yet established, and because it is recognised that significant Alzheimer's pathology can exist at post mortem in individuals who were not judged to be symptomatic in their lifetime. ${ }^{12-15}$ The designation of presymptomatic $\mathrm{AD}$ was proposed for the few individuals who carry an autosomal dominant monogenic AD mutation with virtually full penetrance, in view of the inevitability that they will develop clinically manifest AD. The 2010 lexicon also proposed working definitions of "atypical AD" and "mixed AD". Biomarkers were further categorised as "pathophysiological" if they were direct invivo indicators of brain amyloidosis and tauopathy, including amyloid tracer PET scans and CSF concentrations of $A \beta_{1-42}, \mathrm{~T}$-tau, and P-tau. On the assumption that Alzheimer's pathology leads to metabolic changes or neuronal loss in connected regions, biomarkers were considered to be "topographical" if they identified downstream brain changes indicative of the regional distribution of Alzheimer's pathology, including medial temporal lobe atrophy on MRI or reduced glucose metabolism in temporoparietal regions on FDG PET. No changes were made to the diagnostic algorithm itself (clinical core plus supportive biomarker evidence), except for the specification of atypical forms of $A D$, which described the less frequent but well defined clinical phenotypic variants of non-amnestic focal cortical syndromes, including logopenic aphasia, posterior cortical atrophy, and frontal variant AD.

The NIA-AA diagnostic criteria, published in 2011, similarly advanced the NINCDS-ADRDA framework to cover the full staging of the disease: asymptomatic (preclinical AD), ${ }^{16}$ predementia (MCI due to AD), ${ }^{17}$ and dementia (due to AD) ${ }^{18}$ These criteria shared many features with the IWG criteria, including the integration of biomarkers in the diagnostic process and the recognition of an asymptomatic biomarker-positive stage. The NIA-AA criteria differ conceptually from the IWG criteria on several points. The NIA-AA proposed three different sets of diagnostic criteria, one for each disease stage. Although both the IWG and NIA-AA criteria recognise that the disease starts before the occurrence of clinical symptoms, the NIA-AA criteria support the diagnosis of AD in asymptomatic individuals with biomarker evidence of $A \beta$ accumulation, ${ }^{16}$ whereas the IWG considers this to be only an at risk of disease state. At both the $\mathrm{MCI}^{17}$ and dementia stages, ${ }^{18}$ the NIA-AA diagnostic framework provides different levels of probabilistic likelihood (high, intermediate, or unlikely) that the syndrome is due to $\mathrm{AD}$ based on biomarker information. The NIA-AA criteria have the advantage of being applicable when no supportive biomarkers are available, albeit at the expense of diagnostic specificity. The IWG criteria are less complex in their semiology, have the advantage of consistency, and are more readily applicable in clinical trials and in clinical diagnosis when biomarkers are available.

Validation of both the IWG and NIA-AA diagnostic criteria is fundamental to progress in the field. Preliminary studies (both retrospective and prospective) done mostly
(S Cappa MD); Department of Clinical Neurosciences, Cognitive Neurorehabilitation, Milan, Italy (S Cappa); Dementia Research Centre, Department of

Neurodegeneration, Institute of Neurology, University College London, London, UK (S Crutch PhD, N C Fox MD); Dementia Research Centre, National Hospital, London, UK (S Crutch); Department of Neurology and Memory Clinic Hospital Network Antwerp (ZNA), Middelheim and Hoge Beuken, Antwerp, Belgium (S Engelborghs MD); Reference Centre for Biological Markers of Dementia, Institute Born-Bunge, University of Antwerp, Antwerp, Belgium (S Engelborghs); Hopitaux Universitaires et Université de Genève, Geneva, Switzerland (Prof G B Frisoni MD); IRCCS Fatebenefratelli, Brescia, Italy (G B Frisoni); HUG Belle-Idée, bâtiment les Voirons, Chêne-Bourg, France (G B Frisoni); Department of Neurosciences, -University of California, San Diego, CA, USA (Prof D Galasko MD); INSERM UMR, Paris, France (M-O Habert MD); AP-HP Groupe Hospitalier Pitié-Salpêtrière, Service de Médecine Nucléaire, Paris, France (M-O Habert); University of Kentucky Alzheimer's Disease Center, Lexington, KY, USA (G A Jicha MD); Karolinska Institutet, Karolinska University Hospital Huddinge, Alzheimer Neurobiology Center, Stockholm, Sweden (A Nordberg MD); Université Lille Nord de France, Lille, France (Prof F Pasquier MD); CHRU, Clinique Neurologique, Hôpital Roger Salengro, Lille, France (F Pasquier); UCSF Memory \& Aging Center, Department of Neurology, University of California, San Francisco, CA, USA (G Rabinovici MD); EA CoBTeK and Memory Center, $\mathrm{CHU}$ University of Nice, UNSA Hôpital de Cimiez 4 av Victoria, Nice, France (Prof P Robert MD); FRACP, Department of Nuclear Medicine and Centre for PET, Austin Health, Heidelberg, Melbourne, VIC, Australia (C Rowe MD); Neurology and the Memory and

Aging Program, Butler Hospital, Department of Neurology and Psychiatry, The 
Warren Alpert Medical School of Brown University, Providence, RI, USA (Prof S Salloway MD); Neurologie de la Mémoire et du Langage, Centre Hospitalier Sainte-Anne, Paris Cedex France (Prof M Sarazin MD); Université Paris 5, Paris, France (M Sarazin); Faculty of

Medicine, Federal University of Minas Gerais, Belo Horizonte, Brazil (LC de Souza); Gerontopole, Pavillon Junod, University Toulouse 3, Toulouse, France

(Prof B Vellas MD); Department of Psychiatry and

Neuropsychology, Alzheimer Centre Limburg, School of Mental Health and Neuroscience, Maastricht University Medical Centre, Maastricht and Department of Neurology and Alzheimer Center, Amsterdam, Netherlands (P J Visser MD); Department of Psychiatry, Neurology, and Gerontology, Keck School of Medicine of USC, Los Angeles, CA, USA (Prof L Schneider MD); Cognitive Neuroscience Division of the Taub Institute, Presbyterian Hospital, New York, NY, USA (ProfY Stern PhD); Alzheimer Centrum Vrije Universiteit Medical Center, VU University, Amsterdam, Netherlands (Prof P Scheltens MD); and Lou Ruvo Center for Brain Health, Cleveland Clinic, Las Vegas, NV, USA (Prof J L Cummings MD) Correspondence to: Prof Bruno Dubois, Centre des Maladies Cognitives et Comportementales,

Pavillon F Lhermitte, Salpêtrière Hospital, 47 Bld de l'hôpital, 75013 Paris, France bruno.dubois@psl.aphp.fr with patients referred to memory clinics indicate moderate sensitivity and high specificity for the IWG criteria, with a good diagnostic accuracy (from $93 \%$ to $100 \%$ compared with the NINCDS-ADRDA clinical criteria and, for one study, with the neuropathological Consortium to Establish a Registry for Alzheimer's disease [CERAD] criteria) when several biomarkers are combined. ${ }^{19-23}$ The emphasis and progress on biomarkers builds on an increasingly robust scientific foundation as data emerge about biomarker performance (reliability, reproducibility, validity) and operationalisation (cutoff scores, sensitivity and specificity for AD). ${ }^{24}$ The most challenging questions for both the IWG and NIA-AA frameworks focus on the multitude of proposed biomarkers, their inter-relationships particularly with regard to producing additive value, and their putative weight in the diagnosis. A temporal order has been proposed in the NIA-AA research criteria for preclinical $\mathrm{AD}$, in which amyloid biomarker changes precede neuronal injury in the progression to symptomatic stages. This ordering is not settled, although it has received some support from the cross-sectional baseline data of genetically identified early-onset familial AD cases with various presenilin and amyloid precursor protein mutations. ${ }^{25-27}$

In this Position Paper, the IWG presents evidence to support a refinement of its diagnostic algorithm based on the weighting of biomarkers, which is achieved by reconsidering the biomarker categories and their role as markers of Alzheimer's pathology.

\section{Methods}

The IWG recognised the limitations of the initial criteria and the need to take advantage of rapid progress in the field, and considered that the criteria for the diagnosis of AD might be improved in the light of a more comprehensive body of evidence than was available at their initial formulation in 2007. For this update, an extensive review of the literature was undertaken by BD and LCdS with key search themes (AD diagnosis, preclinical states, prodromal $\mathrm{AD}$, atypical and mixed $\mathrm{AD}$, CSF and neuroimaging, amyloid PET) in PubMed from 2007 until January, 2013. On the basis of a review of selected papers (BD and LCdS), an early draft of the revised conceptual framework was developed (BD, HHF, CJ, PS, and JLC), which was then circulated to the IWG experts for their extensive feedback and electronic consultations within the group. The feedback resulted in a more advanced version of the diagnostic framework and the draft manuscript. It was then proposed to a broader group of experts (JLM, KB, DS, SCa, SE, M-OH, AN, GR, $\mathrm{CR}, \mathrm{BV}$, and LS) for their additional comments in specific areas. The final version was approved by all the authors.

\section{A revised diagnostic algorithm for typical $A D$} New evidence on tests to identify AD memory disorders Memory disorders that manifest as free recall deficits occur in many brain diseases other than $\mathrm{AD}^{28-30} \mathrm{~A}$ specific episodic memory disorder has been reported in $\mathrm{AD}$, which is the manifestation of a hippocampal dysfunction ${ }^{4}$ and can be identified by tests that include list learning. Of these, the free and cued selective reminding test (FCSRT) was specifically recommended in the 2007 criteria because of two major advantages: it controls for a successful encoding (achieved by cued recall) and it facilitates retrieval processing (with the same semantic cues). ${ }^{31}$ There is evidence to support the choice of the FCSRT as a valid clinical marker of typical AD. On one version of the test applied in patients referred to a specialised memory clinic, a low total recall performance, despite retrieval facilitation with cueing, had an excellent specificity for $A D,{ }^{32}$ whereas a low free recall had a specificity of $92 \%$ for identification of people with amnestic MCI who would progress to AD dementia. ${ }^{33}$ The FCSRT had better reported predictive validity than did the Wechsler Memory Scale (WMS) logical memory immediate recall test for identification of both individuals from a communitybased cohort with memory complaints who went on to develop incident AD dementia ${ }^{34}$ and patients referred to a memory clinic who fulfilled broad criteria for MCI and had a characteristic positive CSF profile for Alzheimer's pathology. ${ }^{35}$ Furthermore, impaired FCSRT performance can be correlated with hippocampal atrophy, ${ }^{10}$ grey matter loss of the medial temporal lobe, ${ }^{23}$ and the presence of Alzheimer's pathology as shown by CSF changes, ${ }^{23,35-37}$ even at a prodromal stage. ${ }^{34}$ Different cutoff scores have been considered ${ }^{33}$ and are currently being deployed in several clinical trials in prodromal or early $\mathrm{AD}$, including studies of $\gamma$-secretase inhibitors, BACE inhibitors, monoclonal antibodies, and medical foods. The challenge of prescribing cutoff points lies in the variations in the tests used and in the adjustments across populations for age and education. For research purposes-clinical trials, validation of new biomarkers, or follow-up of patient cohorts-the general approach is to recommend that cutoff points are selected within given target populations that have high specificity for an early AD diagnosis, potentially at the expense of lower sensitivity. Optimisation of the specificity of the memory screen might be a goal to minimise unnecessary additional testing. ${ }^{34}$ Simplified versions of the test based on cued recall can be used for bedside testing. These versions were reported to predict progression to AD dementia in patients with MCI with specificity around $90 \% .^{38-40}$

Other memory tests, particularly those based on list learning and delayed recall, can also be effective in identification of the amnestic syndrome of AD. These tests include different versions of the paired-associate learning and the Rey auditory verbal learning tasks. ${ }^{41-48}$ Other promising neuropsychological tests to detect the amnestic impairments that are specific for early pathological involvement of the entorhinal-perirhinal cortex include the DMS $48,{ }^{49}$ a visual recognition test that 
is correlated with an $\mathrm{AD}$ pattern in patients with $\mathrm{MCI},{ }^{50}$ and the topographical memory test. ${ }^{51}$ The short-term memory binding test might also be a good marker for $\mathrm{AD},{ }^{52}$ given its high specificity in patients with familial $\mathrm{AD}$ and in asymptomatic carriers with PSEN1 autosomal dominant gene mutations. ${ }^{53}$ For all of these tests, evidence for their diagnostic utility for AD should be available before they can be recommended for use within the diagnostic algorithm.

In conclusion, the aggregate evidence continues to support the presence of an amnestic syndrome of the hippocampal type as the clinical core criterion for typical $\mathrm{AD}$, which can be best identified with a list-learning memory test such as the FCSRT or other episodic memory tests with established high specificity for AD across the disease.

\section{The evidence for refining the biomarker criteria}

CSF biomarkers and amyloid PET have both shown the highest specificity when correlated with the underlying Alzheimer's pathology in post-mortem studies. Conceptually, they are the most specific biomarkers to determine that an individual is within the AD continuum even several years before the clinical onset of disease.

CSF pathophysiological markers for AD include $A \beta_{1-42}$, which inversely reflects the brain amyloid burden; T-tau, which directly reflects the intensity of neuronal degeneration; and P-tau, which is believed to be a direct marker of tangle pathology. ${ }^{54}$ Recent studies suggest that CSF markers of $A \beta_{1-42}$ and tau correlate closely with postmortem Alzheimer's pathology. ${ }^{55-60}$ In an autopsy cohort, low CSF $A \beta_{1-42}$ concentrations had a sensitivity of $96.4 \%$ for $\mathrm{AD}$ detection ${ }^{55}$ and CSF markers significantly increased the diagnostic accuracy in clinically uncertain cases. ${ }^{61}$ Of CSF markers, P-tau ${ }_{181}$ concentrations were the most accurate to distinguish AD from non-AD dementias, even in autopsy-confirmed dementia patients. ${ }^{56,62} \mathrm{~A}$ marked reduction in CSF $\mathrm{A} \beta_{1-42}$ and in the $\mathrm{A} \beta_{1-42} / \mathrm{A} \beta_{1-40}$ ratio has consistently been noted in patients at different stages of $\mathrm{AD} .{ }^{54,63}$ However, an isolated low $\mathrm{A} \beta_{1-42}$ is not sufficiently specific to diagnose $A D$, in view of similar findings in some patients with non-AD dementias (Lewy body disease or vascular dementia), given its presence long before onset of clinical $\mathrm{AD}$, or given $\mathrm{AD}$ copathology in patients with Lewy body disease. $^{64}$ Additionally, $\mathrm{A} \beta_{1-42}$ concentrations are particularly sensitive to preanalytical and analytical biases $^{65}$ and make it difficult to achieve the requisite low coefficient of variation and quality control. ${ }^{66}$ Numerous studies have shown that a combination of these CSF biomarkers is required because it significantly improves their discriminative accuracy, ${ }^{67-72}$ but no consensus has been agreed yet as to which specific combination has the greatest utility in $\mathrm{AD}$ diagnosis.

The added value of the combinations of CSF markers has been tested in predictive studies of progression to $\mathrm{AD}$ dementia. Individuals with a high ratio of T-tau to
$A \beta_{1-42}$ or of $\mathrm{P}-\mathrm{tau}_{181}$ to $\mathrm{A} \beta_{1-42}$ progress to symptomatic cognitive impairment (ie, CDR $>0$ ) more quickly than do the remainder of the cohort. ${ }^{67}$ This result was not observed for $A \beta_{1-42}$ concentrations alone for the duration of the longitudinal studies (3-5 years) completed to date. The combination of T-tau, $A \beta_{1-42}$, and P-tau is highly predictive of $\mathrm{AD}$ dementia, ${ }^{72-74}$ which has been confirmed in three large multicentre studies-namely, the Alzheimer's Disease Neuroimaging Initiative (ADNI) study, ${ }^{62}$ the Development of Screening Guidelines and Criteria for Predementia Alzheimer's Disease (DESCRIPA) study, ${ }^{75}$ and the Swedish Brain Power (SBP) project. ${ }^{76} \mathrm{~A}$ meta-analysis recently confirmed that the combination of CSF $A \beta_{1-42}$ with either T-tau or P-tau has the highest predictive accuracy, whereas individual markers were also predictive but with lower accuracy (odds ratio [OR] $7 \cdot 5-8 \cdot 1$ )..$^{7}$ Studies of autosomal dominant mutation carriers, including the Dominantly Inherited Alzheimer's Disease (DIAN) project, also show that high CSF T-tau and P-tau combined with a decrease in CSF $A \beta_{1-42}$ and the ratio of $A \beta_{1-42}$ to $A \beta_{1-40}$ are present 10-15 years before the first symptoms of dementia. $^{25,78,79}$ Thus, data so far indicate that the combination of $A \beta_{1-42}$ with either T-tau or P-tau has the best specificity, but evidence is insufficient with regard to the predictive value and diagnostic accuracy (sensitivity, specificity, negative predictive value, and positive predictive value) of $A \beta_{1-42}$ alone. Additionally, the combined analysis of the CSF biomarkers provides the best accuracy in the differential diagnosis between AD and other degenerative dementias, ${ }^{80-82}$ with a good concordance with post-mortem diagnosis. ${ }^{81,83}$ In particular, the ratio of T-tau to $\mathrm{A} \beta_{1-42}$ was the best biomarker to differentiate AD from frontotemporal lobar degeneration, and showed a specificity of $96.6 \%$ in a series of patients with diagnostic confirmation either by genetics or by post-mortem examination. ${ }^{80}$

In conclusion, $A \beta_{1-42}$ and tau (T-tau or P-tau) should be used in combination, and the CSF AD signature, which combines low $\mathrm{A} \beta_{1-42}$ and high T-tau or P-tau concentrations, significantly increases the accuracy of AD diagnosis even at a prodromal stage. ${ }^{67,73,7,83,84}$ This combination reaches a sensitivity of $90-95 \%$ and a specificity of about $90 \%$ in AD. ${ }^{81,85}$ CSF biomarkers cannot be used as standalone tests, and should be interpreted in a larger clinical context with confounding factors taken into account. An important concern is the large variability in CSF measures between laboratories ${ }^{82}$ and across techniques, ${ }^{86}$ and the lack of agreement on cutoff thresholds. ${ }^{87}$ These variations have made direct comparison of study results difficult. Several programmes of standardisation, including the Alzheimer's Association Quality Control programme for CSF biomarkers, initiatives within the Joint Program for Neurodegenerative Diseases, and the Global Biomarker Standardisation Consortium, ${ }^{88-90}$ and by industry, will minimise between-laboratory variations in the future and allow identification of uniform cutoff levels. 
PET imaging with amyloid tracers, including ${ }^{11} \mathrm{C}-\mathrm{PiB}$, florbetapir (AV-45), ${ }^{91}$ flutemetamol (18F-PiB derivative), florbetaben (AV-1), and AZD4694, ${ }^{92}$ provides important information about the extent of $A \beta$ neuritic plaque burden in the brain. Amyloid PET is therefore considered as a surrogate marker of brain fibrillar amyloid pathology. Both quantitative and qualitative measures of amyloidopathy with PET ligands have correlated strongly with postmortem senile neuritic plaque pathology across PET ligands ${ }^{93-97}$ and shown good predictability for progression to $\mathrm{AD}$ dementia in heterogeneous groups of patients with MCI. ${ }^{98-101}$ Agreement between florbetapir amyloid PET images and post-mortem results reaches $96 \%{ }^{93}$

In conclusion, amyloid PET is a validated pathophysiological marker for fibrillar amyloid, particularly neuritic plaques and amyloid angiopathy. In view of the good correlation with post-mortem diagnosis of $\mathrm{AD}$, a positive amyloid PET can be considered, by extension, as a good marker of Alzheimer's pathology.

As with CSF, there are several issues with the methods of assessment and their interpretation. Visual interpretations of $18 \mathrm{~F}$ amyloid tracers require experienced raters. Tracer sensitivity for moderate amyloid burden is less established and varies according to the age of patients. ${ }^{102}$ The significance of the frequent cases of amyloid PET positivity in asymptomatic individuals requires further investigation, ${ }^{97,103,104}$ which also holds true for the rare cases of amyloid PET-negative individuals with $\mathrm{AD}$ autosomal dominant mutations ${ }^{105}$ or postmortem evidence of fibrillar amyloid. ${ }^{106,107}$

For the purposes of the proposed refinement of the IWG diagnostic criteria, it is important to compare the diagnostic accuracy of CSF markers (low $\mathrm{A} \beta$ and high T-tau or P-tau concentrations) to that of a positive fibrillar amyloid PET scan, given that they gauge somewhat different aspects of AD pathophysiology. CSF $A \beta_{1-42}$ measures soluble forms of $A \beta$, and a low concentration suggests that significant parenchymal deposition has occurred, whereas amyloid imaging directly identifies fibrillar A $\beta$. CSF T-tau and CSF P-tau reflect neuronal degeneration and hyperphosphorylation of tau in the brain, respectively. Despite these distinctions, a recent study has shown equal ability of CSF and amyloid imaging markers to identify individuals at risk of incident cognitive impairment. ${ }^{108}$ Results from this study showed that individuals with increased ligand retention in amyloid imaging typically have decreased CSF $A \beta$ and increased CSF tau concentrations, rather than $A \beta$ alone. In the pathophysiological evolution of $\mathrm{AD}$, substantial deposition of fibrillar amyloid is likely to co-occur with changes in both CSF A $\beta_{1-42}$ and tau, at least at a time shortly before the onset of clinical symptoms. Despite reports of discrepancies, ${ }^{105}$ a high degree of correlation and agreement exists between CSF markers of $A \beta_{1-42}$ and tau, and brain amyloid binding. Amyloid ligand retention on PET has consistently correlated inversely with CSF concentrations of $A \beta_{1-42}{ }^{109-111}$ even in cognitively healthy patients, ${ }^{112}$ which supports the concept of a physiological link between CSF $A \beta_{1-42}$ concentrations and brain amyloidosis. By contrast with the well documented correlation between brain amyloid retention and CSF $A \beta_{1-42}$ concentrations, only a modest agreement was noted between amyloid PET and P-tau. ${ }^{11}$ More recently, the ratios of tau(s) to $A \beta_{1-42}$ outperformed each single biochemical analyte (including $A \beta_{1-42}$ ) in distinguishing PiB-positive from PiB-negative individuals. ${ }^{87}$ The good agreement between CSF markers and PET amyloid imaging provides converging evidence for their validity. ${ }^{114}$

In conclusion, Alzheimer's pathology can be suspected in vivo at any stage of the disease, including preclinical states, by a CSF signature of low $A \beta_{1-42}$ and high T-tau or P-tau concentrations, or by evidence of significant PET amyloid retention (either by visual assessment in advanced cases or by assessment of global cortical threshold in intermediate or difficult cases).

\section{Proposed revision for typical AD}

A research diagnosis of typical $\mathrm{AD}$ can be made in the presence of an amnestic syndrome of the hippocampal type that can be associated with various cognitive or behavioural changes, and at least one of the following changes indicative of in-vivo Alzheimer's pathology: a CSF profile consisting of decreased $A \beta_{1-42}$ levels together with increased T-tau or P-tau concentrations, or an increased retention on amyloid tracer PET. The proposed diagnostic change for typical AD is to include only pathophysiological markers of Alzheimer's pathology (panel 1).

\section{A revised diagnostic algorithm for atypical AD The case for refining the diagnostic algorithm}

In an estimated $6-14 \%$ of cases, ${ }^{115-117}$ the presentation of $\mathrm{AD}$ varies from the typical amnestic form. Patients with an atypical clinical presentation probably account for most of the $11 \%$ of AD cases with an atypical pathological distribution at autopsy. ${ }^{118}$ Each of these atypical forms of $\mathrm{AD}$ presents with a relative preservation of memory plus a recognisable (or characteristic) phenotype that might be accompanied by topographical evidence of brain damage (regional atrophy or hypometabolism) in related regions. Atypical forms of AD generally occur with an earlier age at onset than does typical amnestic AD. It is now possible to propose more precise definitions for atypical AD presentations, including a posterior variant of $\mathrm{AD}$, a logopenic variant of $\mathrm{AD}$, and a frontal variant of $\mathrm{AD}$.

The posterior variant of $\mathrm{AD}$ presents as a posterior cortical atrophy ${ }^{119}$ and generally results in several signs and symptoms that distinguish two subtypes: ${ }^{120}$ an occipitotemporal variant, ${ }^{115}$ with a predominant impairment in the visual identification of objects, symbols, words, or faces; and a more common biparietal variant, ${ }^{121}$ with predominant visuospatial dysfunction, as well as features of Gerstmann or Balint syndrome, limb apraxia, or neglect. The logopenic variant of $\mathrm{AD}$, which presents as the 
logopenic primary progressive aphasia, is defined by a progressive impairment in single-word retrieval and in repetition of sentences in the context of spared semantic, syntactic, and motor speech abilities. ${ }^{122}$ The frontal variant of $\mathrm{AD}$ presents as a behavioural variant of frontotemporal dementia, with progressive apathy or behavioural disinhibition and stereotyped behaviours, or with predominant executive dysfunction at testing. ${ }^{123-128}$

Although most cases of posterior cortical atrophy and logopenic primary progressive aphasia are linked to Alzheimer's pathology, ${ }^{126,129}$ only a few patients who present with prominent frontal behavioural symptoms have Alzheimer's pathology detected post mortem. ${ }^{126,128,130}$ As for typical AD, the IWG emphasises the necessity of pathophysiological biomarkers to support a diagnosis of $\mathrm{AD}$ in these atypical cases (panel 2). The topographical biomarkers can help to characterise the clinical phenotype (regional cortical hypometabolism in FDG PET, circumscribed cortical atrophy on structural MRI), whereas a positive pathophysiological biomarker is required to link the phenotype to the underlying Alzheimer's pathology. ${ }^{131-133}$ Although a positive pathophysiological biomarker supports the presence of Alzheimer's pathology, it does not exclude the cooccurrence of non-AD pathology, which might be a significant contributor to the atypical syndromes, particularly in the frontal variant, ${ }^{134}$ which is less predictive of pure underlying $\mathrm{AD}$ than the logopenic or posterior variants. By definition, these atypical syndromes can be diagnosed within their prodromal phase as well as into the dementia continuum along a spectrum of severity. Further work is needed to distil the specific clinical core related to Alzheimer's pathology in each of these atypical presentations, with the aim of characterising the clinically atypical cores with the same conceptual foundation in cognitive theory and operationalisation in terms of test paradigms as has been done for the amnestic core in typical AD.

The occurrence of a dementia in patients with Down's syndrome can be classified as an atypical AD because the clinical phenotype associated with the occurrence of Alzheimer's pathology is dominated by changes in behaviour, executive functions, and functional activities. ${ }^{135}$ The premorbid intellectual disability creates a specific setting for the assessment of the cognitive impairment associated with Alzheimer's pathology. Although episodic memory changes can be identified with testing procedures, the presenting functional and behavioural symptoms lead to their consideration as atypical AD.

\section{Proposed revision for atypical $A D$}

A diagnosis of atypical AD can be made in the presence of the following: a clinical phenotype that is consistent with one of the known atypical presentations (posterior variant, logopenic variant of primary progressive aphasia, frontal variant) and at least one of the changes indicating in-vivo Alzheimer's pathology (panel 2).
Panel 1: IWG-2 criteria for typical AD (A plus B at any stage)

\section{A Specific clinical phenotype}

- Presence of an early and significant episodic memory impairment (isolated or associated with other cognitive or behavioural changes that are suggestive of a mild cognitive impairment or of a dementia syndrome) that includes the following features:

- Gradual and progressive change in memory function reported by patient or informant over more than 6 months

- Objective evidence of an amnestic syndrome of the hippocampal type, ${ }^{*}$ based on significantly impaired performance on an episodic memory test with established specificity for $A D$, such as cued recall with control of encoding test

B In-vivo evidence of Alzheimer's pathology (one of the following)

- Decreased $A \beta_{1-42}$ together with increased T-tau or P-tau in CSF

- Increased tracer retention on amyloid PET

- $A D$ autosomal dominant mutation present (in PSEN1, PSEN2, or APP)

\section{Exclusion criteria $\uparrow$ for typical $A D$}

History

- Sudden onset

- Early occurrence of the following symptoms: gait disturbances, seizures, major and prevalent behavioural changes

Clinical features

- Focal neurological features

- Early extrapyramidal signs

- Early hallucinations

- Cognitive fluctuations

Other medical conditions severe enough to account for memory and related symptoms

- Non-AD dementia

- Major depression

- Cerebrovascular disease

- Toxic, inflammatory, and metabolic disorders, all of which may require specific investigations

- MRI FLAIR or T2 signal changes in the medial temporal lobe that are consistent with infectious or vascular insults

$\mathrm{AD}=\mathrm{Alzheimer}$ 's disease. *Hippocampal amnestic syndrome might be difficult to identify in the moderately severe to severe dementia stages of the disease, in which in-vivo evidence of Alzheimer's pathology might be sufficient in the presence of a well characterised dementia syndrome. †Additional investigations, such as blood tests and brain MRI, are needed to exclude other causes of cognitive disorders or dementia, or concomitant pathologies (vascular lesions).

\section{A revised diagnostic algorithm for mixed $A D$ \\ The case for refining the diagnostic algorithm}

The IWG initially defined mixed AD as the co-occurrence of Alzheimer's pathology with other pathologies that might contribute to the cognitive decline, such as normal pressure hydrocephalus, hippocampal sclerosis, and most often cerebrovascular disease or Lewy body disease. ${ }^{11}$ Mixed AD has been reported to represent at least $50 \%$ of all $\mathrm{AD}$ cases at autopsy, with a particularly high prevalence in people older than 80 years. ${ }^{136,137}$ The recognition of mixed pathology in clinical diagnosis is challenging. ${ }^{138}$ Our current proposal for mixed AD diagnosis is that there must be evidence of AD based on clinical phenotype, either typical or atypical, with concurrent in-vivo evidence of Alzheimer's pathology. Additionally, clinical as well as 
Panel 2: IWG-2 criteria for atypical AD (A plus B at any stage)

\section{A Specific clinical phenotype (one of the following)}

- Posterior variant of AD (including)

- An occipitotemporal variant defined by the presence of an early, predominant, and progressive impairment of visuoperceptive functions or of visual identification of objects, symbols, words, or faces

- A biparietal variant defined by the presence of early, predominant, and progressive difficulty with visuospatial function, features of Gerstmann syndrome, of Balint syndrome, limb apraxia, or neglect

- Logopenic variant of AD defined by the presence of an early, predominant, and progressive impairment of single word retrieval and in repetition of sentences, in the context of spared semantic, syntactic, and motor speech abilities

- Frontal variant of AD defined by the presence of early, predominant, and progressive behavioural changes including association of primary apathy or behavioural disinhibition, or predominant executive dysfunction on cognitive testing

- Down's syndrome variant of AD defined by the occurrence of a dementia characterised by early behavioural changes and executive dysfunction in people with Down's syndrome

B In-vivo evidence of Alzheimer's pathology (one of the following)

- Decreased A $\beta_{1-42}$ together with increased T-tau or P-tau in CSF

- Increased tracer retention on amyloid PET

- Alzheimer's disease autosomal dominant mutation present (in PSEN1, PSEN2, or APP)

Exclusion criteria* for atypical AD

History

- Sudden onset

- Early and prevalent episodic memory disorders

Other medical conditions severe enough to account for related symptoms

- Major depression

- Cerebrovascular disease

- Toxic, inflammatory, or metabolic disorders

$\mathrm{AD}=$ Alzheimer's disease. *Additional investigations, such as blood tests and brain MRI, are needed to exclude other causes of cognitive disorders or dementia, or concomitant pathologies (vascular lesions).

Panel 3: IWG-2 criteria for mixed AD (A plus $B$ )

A Clinical and biomarker evidence of $A D$ (both are required)

- Amnestic syndrome of the hippocampal type or one of the clinical phenotypes of atypical $A D$

- Decreased $A \beta_{1-42}$ together with increased T-tau or P-tau in CSF, or increased tracer retention on amyloid PET

B Clinical and biomarker evidence of mixed pathology

For cerebrovascular disease (both are required)

- Documented history of stroke, or focal neurological features, or both

- MRI evidence of one or more of the following: corresponding vascular lesions, small vessel disease, strategic lacunar infarcts, or cerebral haemorrhages

For Lewy body disease (both are required)

- One of the following: extrapyramidal signs, early hallucinations, or cognitive fluctuations

- Abnormal dopamine transporter PET scan

$A D=$ Alzheimer's disease neuroimaging or biochemical evidence of a non-AD contributing disorder should be present. For example, in the case of Lewy body disease, additional clinical features of visual hallucinations, extrapyramidal signs, rapid eye movement (REM) sleep behaviour disorder, or cognitive fluctuations ${ }^{139}$ would be supported by a positive dopamine transporter imaging test. ${ }^{140}$. For cerebrovascular disease, the clinical presentation would include a history of stroke, appropriate vascular risk factors or focal neurological findings (or both), which should be supported by neuroimaging evidence of cerebrovascular disease in the form of lacunar disease, evidence of cerebral amyloid angiopathy, large or small vessel territory infarctions, extensive leukoaraiosis, or small vessel disease (panel 3).

The clinical phenotype of mixed AD is uncertain. AD and non-AD dementias are not easily catalogued into distinct, non-overlapping clinical and neuropsychological profiles. ${ }^{141}$ A few autopsy-based studies on AD associated with Lewy body disease have shown episodic memory impairment similar to that noted in $\mathrm{AD}$ alone, with visuospatial deficits unusually severe for $\mathrm{AD}^{142}$ and with milder impairment in executive functioning than usually found in Lewy body disease. ${ }^{143}$ AD combined with cardiovascular disease might also present with a distinct profile of deficits, probably broader than that of $\mathrm{AD}$ alone. ${ }^{144,145}$ These and other mixed AD clinical presentations need to be carefully characterised, particularly at the prodromal stage.

\section{Proposed revision for mixed AD}

A diagnosis of mixed $A D$ can be made in patients with typical or atypical clinical phenotypic features of $\mathrm{AD}$ and the presence of at least one biomarker of Alzheimer's pathology. This evidence is needed to establish the AD contribution to the mixed disorder. The coexisting disorder within the mixed diagnosis is identified by additional evidence of specific clinical and biological features of the other disease, such as parkinsonism or cerebrovascular disease (panel 3).

\section{Criteria for the preclinical states of $A D$ The case for new criteria for the diagnosis of preclinical} states

The disappointing results of drugs targeting $A \beta$ in recent clinical trials for patients with mild to moderately severe $\mathrm{AD}$ have engendered the belief that these therapies are being tested too late in the process of the disease and that earlier intervention is needed to ameliorate the course of AD. ${ }^{146,147}$ In turn, interest has intensified in defining the preclinical states of AD through research projects on the natural history and trajectory of the disease, to design secondary preventive clinical trials. ${ }^{148,149}$ Pathophysiological biomarkers of disease, independent of disease stage, makes it possible to identify patients considered to be asymptomatic at risk for $\mathrm{AD} .{ }^{12}$ In preclinical states, data for early CSF changes are needed because it may be possible that an isolated low $A \beta_{1-42}$ concentration is 
sufficient to identify asymptomatic at-risk patients at this time. ${ }^{36}$ Cognitively normal patients with isolated low concentrations of $A \beta$ present significant changes in both cortical thickness and fMRI, ${ }^{36,150}$ which suggests that at the start of the preclinical state, amyloid might be the only positive marker, as proposed by Jack and colleagues..$^{99}$ By contrast, the identification of relatively common genetic risk variants such as $C L U, C R 1$, and PICALM ${ }^{151,152}$ is of limited interest in the determination of risk of the preclinical state of $\mathrm{AD}$ in the general population. Even the $A P O E$ \&4 allele, associated with AD risk, is neither necessary nor sufficient for development of the disease. ${ }^{153}$

Although a long insidious preclinical state of the disease can precede the onset of clinical symptoms by many years, the risk factors and timing for development of clinically expressed AD from the asymptomatic at-risk state are not characterised sufficiently well to move beyond this diagnostic designation. To be asymptomatic at risk, individuals should not have clinical evidence of prodromal AD. The existence of any cognitive changes or complaints does not necessarily signify progression to clinical AD because these could be non-specific changes. There is an emerging trend to consider that $\mathrm{AD}$ can be identified clinically in the case of subtle cognitive changes. ${ }^{17}$ Isolated subjective memory complaints and the recent concept of subjective cognitive decline ${ }^{154}$ could be predictors of subsequent cognitive decline and progression to dementia ${ }^{155}$ and might be associated with brain amyloid deposition on amyloid PET. ${ }^{15,157}$ However, subjective memory complaints are only a risk factor for $\mathrm{AD}$, because they might result from many other causes frequently encountered in the ageing population, including attention difficulties, depressed mood, sleep disorders, and drug side-effects. According to the refined IWG criteria proposed here, the diagnosis of AD requires the identification of one of the specific clinical phenotypes of the disease. A similar approach is advocated for presymptomatic $\mathrm{AD}$, with progression to clinical $\mathrm{AD}$ certified only by the presence of objective clinical symptoms characteristic of the disease (panel 1).

\section{Proposed revision for preclinical states}

Research criteria for preclinical states of $\mathrm{AD}$ require: the absence of clinical symptoms of AD (typical or atypical phenotypes); and the presence of at least one biomarker of Alzheimer's pathology for the identification of asymptomatic at-risk state, or the presence of a proven $\mathrm{AD}$ autosomal dominant mutation on chromosomes 1, 14, or 21 for the diagnosis of presymptomatic state (panel 4).

\section{Differentiation of biomarkers of AD diagnosis \\ from biomarkers of AD progression \\ Refining the use of pathophysiological and topographical biomarkers}

Alzheimer's pathology consists of brain amyloid deposition and neurofibrillary tangles, generally associated with synaptic loss and vascular amyloid deposits. Where they develop, these lesions induce functional deficits and neuronal death. Variations in the hierarchy and relationships between $\mathrm{A} \beta$ load, cerebral hypometabolism, and atrophy have been reported. ${ }^{158}$ However, these changes account for regional hypometabolism, atrophy of specific structures, and cognitive disorders in relation to the location of the neuronal lesions. Downstream topographical markers, particularly hippocampal atrophy assessed by MRI, cortical hypometabolism measured by FDG PET, and the subsequent cognitive and behavioural changes lack pathological specificity for $\mathrm{AD}$, but they might be particularly valuable for detection and quantification of disease progression. These changes might be good markers to monitor time to disease milestones - eg, dementia onset — or for determination of disease stages. ${ }^{25,99}$

Among all MRI-related biomarkers-including structural MRI with assessment of atrophy of critical brain regions (parahippocampal gyrus, hippocampus, amygdala, posterior association cortex, and subcortical nuclei including the cholinergic basal forebrain), assessment of cortical thickness, ${ }^{159}$ and with use of support vector machine-based classifier; ${ }^{160}$ functional MRI ${ }^{161,162}$ with studies of activation or functional connectivity; and proton magnetic resonance spectroscopy for the $\mathrm{N}$-acetylaspartate (NAA)/creatine ratio in specific areas (posterior cingulate gyri) ${ }^{163-165}$-it is now established that medial temporal atrophy is the best MRI marker at a prodromal stage of further progression to $\mathrm{AD}$ dementia, and hippocampal atrophy is the most robust. ${ }^{166}$ However, hippocampal volume is reduced in several conditions, including old age, and several neurotoxic situations including diabetes, sleep apnoea, bipolar disorder, and other conditions or dementia

Panel 4: IWG-2 criteria for the preclinical states of $A D$

IWG-2 criteria for asymptomatic at risk for AD (A plus B)

A Absence of specific clinical phenotype (both are required)

- Absence of amnestic syndrome of the hippocampal type

- Absence of any clinical phenotype of atypical $A D$

$B$ In-vivo evidence of Alzheimer's pathology (one of the following)

- Decreased $A \beta_{1-42}$ together with increased T-tau or P-tau in CSF

- Increased retention on fibrillar amyloid PET

IWG-2 criteria for presymptomatic AD (A plus B)

A Absence of specific clinical phenotype (both are required)

- Absence of amnestic syndrome of the hippocampal type

- Absence of any clinical phenotype of atypical AD

B Proven AD autosomal dominant mutation in PSEN1, PSEN2, or APP, or other proven genes (including Down's syndrome trisomy 21)

$A D=$ Alzheimer's disease 
(hippocampal sclerosis, Lewy-related pathology, argyrophilic grain disease, and frontotemporal dementia). ${ }^{167-169}$ Additionally, some pathological studies have documented the existence of hippocampal sparing in $\mathrm{AD}$, often associated with early age-of-onset and nonamnestic clinical presentations, in which cortical degeneration is predominant while the medial temporal lobes are relatively spared. ${ }^{118,170,171}$ The association of all these non-AD disorders decreases the diagnostic utility of volumetric measures of medial temporal lobe structures for individual diagnostic purposes. However, the reliability of volumetric measures obtained from repeated MRI scans is high, ${ }^{172}$ which allows the study of the rate of atrophy over time as a reliable modality to measure disease progression. For example, hippocampal loss occurs at a rate that is approximately two to four times faster in patients with $\mathrm{AD}$ than in age-matched healthy controls. ${ }^{173,174}$

Among topographical markers, FDG PET has been shown to have good sensitivity in detection of early brain dysfunction in $\mathrm{AD}^{175-17}$ and to follow disease evolution over time, ${ }^{178-181}$ including in AD mutation carriers. ${ }^{182,183}$ FDG uptake is believed to be a sensitive marker of synaptic dysfunction, ${ }^{184,185}$ and understandably the topography of hypometabolism accurately maps on clinical symptoms. Patients with $\mathrm{AD}$ with predominant memory impairment show the classic default mode network pattern (temporoparietal association areas including the precuneus and posterior cingulate cortex), whereas in patients with AD with focal neuropsychological deficits (language, praxis, or visuospatial dysfunction) hypometabolism affects the pertinent neocortical area. ${ }^{186,187} \mathrm{~A}$ study of the accuracy to predict progression from MCI to dementia in 102 patients reported values of $95 \%$ sensitivity and $79 \%$ specificity, ${ }^{188}$ and a meta-analysis noted a positive likelihood ratio of $7.5(0.4-14.7)$ and a negative likelihood ratio of $0 \cdot 50(0 \cdot 14-0 \cdot 86) .^{24}$ Changes have also been noted in asymptomatic patients at risk for AD. ${ }^{189-191}$ FDG uptake is

Panel 5: Definition of AD biomarkers

\section{Diagnostic marker}

- Pathophysiological marker

- Reflects in-vivo pathology

- Is present at all stages of the disease

- Observable even in the asymptomatic state

- Might not be correlated with clinical severity

- Indicated for inclusion in protocols of clinical trials

Progression marker

- Topographical or downstream marker

- Poor disease specificity

- Indicates clinical severity (staging marker)

- Might not be present in early stages

- Quantifies time to disease milestones

- Indicated for disease progression

$\mathrm{AD}=$ Alzheimer's disease reduced, predominantly in temporoparietal association areas including the precuneus and posterior cingulate cortex, and these changes are closely related to cognitive impairment as demonstrated in cross-sectional and longitudinal studies. ${ }^{186}$

Therefore, functional tracers such as FDG PET, in addition to their ability to differentiate AD from other neurodegenerative dementias, ${ }^{192-194}$ can help to show the extent to which Alzheimer's pathology affects brain function, particularly in individuals with high cognitive reserve. ${ }^{195-197}$

\section{Proposed revision}

We propose that pathophysiological biomarkers of Alzheimer's pathology and downstream topographical markers of AD should be reconceptualised, whereby biomarkers of Alzheimer's pathology are restricted to those indicating the specific presence of tau pathology (CSF or PET tau) and amyloid pathology (CSF or PET amyloid) (panel 5). These biomarkers have the necessary specificity for a diagnosis of $\mathrm{AD}$ at any point on the disease continuum. Downstream topographical markers of brain regional structural and metabolic changes have insufficient pathological specificity and are therefore now removed from the IWG diagnostic algorithm. These markers can be used to measure disease progression.

\section{Discussion}

In this paper, we refine the IWG research diagnostic criteria for $\mathrm{AD}$ to provide a more simplified algorithm based on specific AD clinical phenotypes with in-vivo evidence of Alzheimer's pathology through either a molecular AD signature in CSF or positive amyloid imaging (figure). This simplified diagnostic algorithm reinforces our understanding of $\mathrm{AD}$ as a clinicobiological entity and allows the application of a single set of diagnostic criteria at any stage of the disease. We broaden the clinical core criteria to include the challenging phenotypic characterisations of atypical and mixed AD. The proposed refinements will place great demands on the clinical core diagnosis, for which the clinician now needs to identify a range of potential AD phenotypes, including mixed AD phenotypes and focal non-amnestic disease presentations.

We reconsider the biomarker support required for these diagnoses by anchoring all diagnostic criteria to the requirement of in-vivo evidence of $\mathrm{AD}$ pathophysiology, defined as increased brain amyloid retention on PET imaging (and perhaps of tau ligand on tau imaging PET in the near future), or as decreased $A \beta_{1-42}$ together with increased $\mathrm{T}$-tau or P-tau in CSF. Low CSF $A \beta_{1-42}$ concentrations alone are not specific enough for an AD diagnosis. These refinements are based on evidence supporting the high specificity of CSF biomarkers and PET amyloid imaging for AD. An important change in the current criteria is that topographical markers of AD are now recommended for the assessment of disease 
stage and progression rather than as diagnostic markers. The classification in the NINCDS-ADRDA criteria of "clinically probable" AD could be discarded now that we are able to identify Alzheimer's pathology in vivo. Additionally, we now integrate the presence of an autosomal dominant genetic mutation for $\mathrm{AD}$ as a diagnostic marker of the disease.

Within the proposed refinements of the IWG diagnostic criteria, we address the problem of the diversity of $\mathrm{AD}$ biomarkers and their potential weighting in the diagnostic algorithm. The IWG previously identified pathophysiological and topographical markers but attributed equal utility to both in the diagnosis of AD. The NIA-AA distinguishes between markers of $A \beta$ deposition and neuronal injury, and assigns each type an equal role in diagnosis. We advance this categorisation through a redefinition of purpose or role of the biomarkers. We view pathophysiological markers as indicators of Alzheimer's pathology in the brain, rather than as markers linked to disease stages. That is, they describe the presence of disease pathology at any stage. These markers of Alzheimer's pathology are largely static, at least in the symptomatic stage of the disease, whereas topographical markers that are linked to the evolution of disease have greater dynamic range and changes over time. These proposed refinements simplify the diagnostic approach by designating a single in-vivo pathophysiological signature of $\mathrm{AD}$, measured either in CSF or by use of amyloid PET.

The proposed revisions still rely on the two fundamental tenets that underlined the initial IWG criteria. The first is that they characterise a disease (AD) and not a syndrome (MCI or dementia). The combination of a specific cognitive profile, consistent with typical or atypical AD, and a positive pathophysiological marker moves the patient from an undetermined status of MCI to that of prodromal AD. The concept of MCI remains useful for cases that are negative for pathophysiological biomarkers. The second tenet is to maintain the principle of high specificity, at least for criteria that apply for research purposes including clinical trials. The 2007 IWG criteria were successfully implemented in current phase 2 clinical trials for prodromal AD and they were qualified for use in AD clinical trials by the European Medicines Agency (EMA). ${ }^{198}$ Identification of patients with typical AD is thought to be more accurate and more reliable based on the refined algorithm. Once the well defined and operationalised core amnestic criterion is met, confirmation from a single positive pathophysiological marker is sufficient for inclusion purposes (except in rare cases of AD in which memory and MRI changes precede amyloid positivity). ${ }^{199}$ To date, we have integrated evidencebased, clinically established, atypical forms of AD. In the future, new potential atypical presentations of AD might be considered and incorporated into our model. Research on patients with atypical or mixed AD will also benefit from the refined algorithm with reference to biomarkers

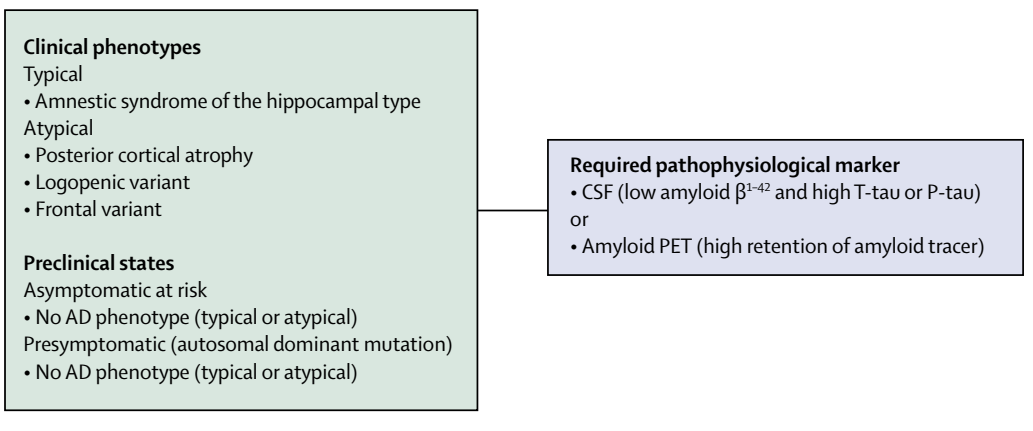

Figure: $A D$ is defined as a clinicobiological entity

A simplified algorithm is proposed: in any condition and at any stage of the disease, the diagnosis of AD relies on the presence of a pathophysiological marker. $A D=$ Alzheimer's disease.

of amyloid pathology. This diagnostic framework should promote more systematic studies of these disorders.

Although the revised algorithm is meant to apply to all stages of the disease, it should be implemented with caution for some conditions, such as for patients with $\mathrm{AD}$ at moderately severe or severe stages for whom intellectual deterioration has progressed to a point at which memory testing is no longer possible. In such circumstances, positive markers of Alzheimer's pathology should be considered as sufficient for inclusion in research on the basis of a history consistent with $\mathrm{AD}$ and after exclusion of a mixed disease with appropriate investigations. Disagreement between pathophysiological markers needs to be considered, and longitudinal observations should help to solve this issue in the future. There might also be age-related limitations. In older patients ( $>85$ years), the clinical expression of $\mathrm{AD}$ and neuroimaging changes might be less salient. ${ }^{200}$ The phenotypic expression of $\mathrm{AD}$ is relatively mild in the oldest-old (>85 years) with a frequently indolent course. ${ }^{201-203}$ The diagnostic performance of CSF biomarkers and of structural MRI-based regional brain atrophy decreases with age, ${ }^{204}$ as does the association between neuritic plaques and dementia. ${ }^{205}$ This decrease in performance might affect the ability to distinguish AD from normal ageing in this group, ${ }^{206}$ for which high fibrillar amyloid is also very often detected. Furthermore, these patients have an increased risk of other systemic comorbidities $^{136}$ and general health problems including inflammatory conditions, anaemia, cancer, frailty, comedications, and other factors, which undoubtedly can interfere with the occurrence, expression, and progression of $\mathrm{AD}$ symptoms ${ }^{207}$ and might render the proposed algorithm less accurate. One refinement for a research perspective might be to separate younger patients, for which $\mathrm{AD}$ is rather pure with fewer or no comorbidities, high diagnostic accuracy, and reliability, from the oldest-old patients with a higher risk of comorbidities and a more complex underlying pathology. Research into individuals with identified risk of AD will continue to present challenges despite our efforts to 
better define the preclinical states of $\mathrm{AD}$. Important clinical issues exist in distinguishing between normal ageing, subtle early AD symptoms, and non-AD symptoms, and careful assessment will be needed to establish whether cognitive changes constitute an early expression of $\mathrm{AD}$. Isolated low CSF levels of $A \beta_{1-42}$ might be present long before the appearance of the disease, and further evidence will tell us whether it might be sufficient to define asymptomatic at-risk patients.

In our view, the proposed criteria, which are designed for the accurate diagnosis of $\mathrm{AD}$ for rigorous research purposes, might in the future be used for clinical diagnosis in practice, at least for young-onset $\mathrm{AD}$ or atypical presentations in which biomarkers might increase diagnostic accuracy. Expert centres with adequate resources could use the algorithm proposed here and assess its performance to move the field forward and to determine utility within clinical practice. Important work has already been done in application of the 2007 IWG criteria in outpatient clinics, with excellent specificity and acceptable sensitivity. ${ }^{20-23}$ There is no a priori reason against a general move of the proposed criteria from research into clinical settings, at least in specific cases, although several caveats need to be considered. Not all centres have PET scanning equipment and expertise, and some participants might not readily accept a lumbar puncture for CSF assays. Further studies are needed to clarify conflicting results that can occur between the different CSF markers, and between CSF markers and amyloid PET. The lack of financial support for these costly investigations may limit the practicality of the IWG-2 criteria for general clinical use. Studies to determine the cost-effectiveness of diagnosis might also be required. Pathophysiological markers allow the identification of Alzheimer's pathology, including amyloidopathy or tauopathy, but do not preclude the presence of other non-AD conditions. MRI and other investigations are still necessary for the identification of comorbid or non-AD conditions and will continue to be part of the diagnostic approach. Cultural acceptance should also be taken into account. Although the use of CSF biomarkers is advancing well in European countries, this is not the case in many Asian ${ }^{208}$ and Latin American countries, ${ }^{209}$ and to some extent even in North America. An important issue in transitioning of the proposed algorithm to general clinical settings is the rendering of a diagnosis of $\mathrm{AD}$ at the prodromal stage, in an era for which effective disease-modifying treatments are not yet available. The potential benefits of such a diagnosis should be weighed against any potential psychological and emotional effects. ${ }^{210,211}$ Alternatively, a misdiagnosis of AD has strong ethical implications, which emphasise the value of high diagnostic accuracy. The choice of a highly specific clinical criterion decreases the risk of a false-positive diagnosis anchored on biomarker results.

In conclusion, we propose a number of refinements to the 2007 IWG diagnostic algorithm and 2010 lexicon for the research diagnosis of AD. The current refinements have been made possible because rapid progress in the field in the past 4 years has improved our characterisation of clinical phenotypes and the expression of disease captured by in-vivo biomarkers of Alzheimer's pathology. We foresee that progress will continue to be rapid and we anticipate that studies of the very early stages of disease will represent a paradigm shift that will result in more successful therapeutic developments.

\section{Contributors}

All authors contributed to the writing and revision of the paper and approved the final version. BD had final responsibility for the decision to submit for publication.

\section{Declaration of interests}

BD has collaborated with Eli Lilly and Affiris, and has received grants for his institution from Roche and Pfizer. HHF was a full-time paid employee of Bristol-Myers Squibb from 2009 to 2011, on leave from the University of British Columbia (UBC), and received salary and stock holdings in this role. Since 2012, he has provided consulting through service agreements with Biogen Idec, Eli Lilly Pharmaceuticals, Kyowa Hakko Kirin, and GE Healthcare, for which UBC received payments. He received a speaker's honorarium from Danone, and has served on advisory boards with Fidelity Biosciences, for which he received travel and meeting expenses. $\mathrm{HH}$ has received honoraria, travel expenses, consulting fees, or research grants from Boehringer lngelheim, Bristol-Myers Squibb, Elan Corporation, Wyeth, Novartis, Eisai, Pfizer, Schwabe, Sanofi-Aventis, Roche Pharmaceuticals and Diagnostics, GE Healthcare, AstraZeneca, Avid, Eli Lilly and Company, Janssen-Cilag, Merz Pharmaceuticals, GlaxoSmithKline Biologicals, Jung Diagnostics, and Thermo Fisher Scientific Clinical Diagnostics BRAHM S GmbH. KB has served on advisory boards for lnnogenetics, Pfizer, and Roche. STDK has worked as a consultant for drug development for Pfizer, Merck, Lilly, Genzyme, AstraZeneca, and Helicon Therapeutics. He is also the principal investigator at the University of Virginia Memory Disorders Clinics for Elan, Novartis, Janssen, Pfizer, and Baxter. DS has been a consultant for Elan Corporation. RB is co-founder and part owner of C2N Diagnostics. He has received grants, consultancy fees, or speaker's fees from AstraZeneca, Merck, a pharma consortium (Biogen Idec, Elan Pharmaceuticals, Eli Lilly and Company, Hoffman-La Roche, Genentech, Janssen Alzheimer's Immunotherapy, Mithridion, Novartis Pharma AG, Pfizer Biotherapeutics R\&D, Sanofi-Aventis, Eisai), Genentech, Roche, and Sanofi. SCa has received honoraria as a conference speaker for Novartis and Serono, and reimbursement for travel grants from Novartis and Nutricia. NCF has received research funding from Janssen, Elan Corporation, Lundbeck, Pfizer, Sanofi, and Wyeth; he has received no personal compensation for these activities. DG has received funding for research and clinical trials from Eli Lilly; he serves on Data and Safety Monitoring Boards for Pfizer, Elan Corporation, and Balance

Pharmaceuticals. AN received honoraria for her participation on scientific advisory boards with Elan Corporation, Merck, GE Healthcare, Lundbeck AB, Pfizer, Avid Radiopharmaceuticals, (a wholly owned subsidiary of Eli Lilly), Johnson \& Johnson, and Cytox; and as a speaker for Novartis, Bayer Health, Janssen-Cilag, Pfizer, Merz, and Envivo. Her department has received grants from GE Healthcare and Bayer Health. FP has received fees for participation on scientific advisory boards for Eli Lilly, Sanofi, Novartis, Janssen, Pfizer, and Nutricia. GR has received consulting fees from Eli Lilly and speaker's honoraria from GE Healthcare. He receives research support from Avid Radiopharmaceuticals. PR has received an honorarium from Lundbeck and Eisai, and has participated in expert meetings for Roche, Lilly, and Elan. CR has received research grants from Bayer/Piramal, GE Healthcare, Avid Radiopharmaceuticals, and AstraZeneca. SS has received honoraria from GE Healthcare, Avid Radiopharmaceuticals/Lilly, Bayer, Bristol-Myers Squibb, Athena, Pfizer, Merck, Roche, Baxter, and Janssen Alzheimer's Immunotherapy; and research grants to his institution from Avid, Janssen Alzheimer's Immunotherapy, Baxter, Bristol-Myers Squibb, Pfizer, Genetech, GE Healthcare, Roche, Merck, and Biogen. PJV has served as an advisory board member for Bristol-Myers Squibb. He receives, and has received, research grants from Bristol-Myers Squibb. LS has received grants and 
research support from Baxter, Genentech, Johnson \& Johnson, Eli Lilly, Lundbeck, Novartis, Pfizer, and Tau Rx. He has served as a consultant for, and received consulting fees from, Abbvie, AC Immune, Allon, AstraZeneca, Baxter, Biogen Idec, Biotie, Bristol-Myers Squibb, Cerespir, Chiesi, Elan, Eli Lilly, EnVivo, GlaxoSmithKline, Johnson \& Johnson, Lundbeck, MedAvante, Merck, Novartis, Piramal, Pfizer, Roche, Servier, Takeda, Tau Rx, Toyama, and Zinfandel. PS received a grant for his institution from GE Healthcare for an investigator-initiated study. All other authors declare no competing interests.

References

1 Dubois B, Feldman HH, Jacova C, et al. Research criteria for the diagnosis of Alzheimer's disease: revising the NINCDS-ADRDA criteria. Lancet Neurol 2007; 6: 734-46.

2 Jack CR Jr, Albert MS, Knopman DS, et al. Introduction to the recommendations from the National Institute on AgingAlzheimer's Association workgroups on diagnostic guidelines for Alzheimer's disease. Alzheimers Dement 2011; 7: 257-62.

3 McKhann G, Drachman D, Folstein M, Katzman R, Price D, Stadlan EM. Clinical diagnosis of Alzheimer's disease: report of the NINCDS-ADRDA Work Group under the auspices of Department of Health and Human Services Task Force on Alzheimer's Disease. Neurology 1984; 34: 939-44.

4 Varma AR, Snowden JS, Lloyd JJ, Talbot PR, Mann DM, Neary D. Evaluation of the NINCDS-ADRDA criteria in the differentiation of Alzheimer's disease and frontotemporal dementia. J Neurol Neurosurg Psychiatry 1999; 66: 184-88.

5 Dubois B, Albert ML. Amnestic MCI or prodromal Alzheimer's disease? Lancet Neurol 2004; 3: 246-48.

6 Lavenu I, Pasquier F, Lebert F, Pruvo JP, Petit H. Explicit memory in frontotemporal dementia: the role of medial temporal atrophy. Dement Geriatr Cogn Disord 1998; 9: 99-102.

7 Pillon B, Deweer B, Michon A, Malapani C, Agid Y, Dubois B. Are explicit memory disorders of progressive supranuclear palsy related to damage to striatofrontal circuits? Comparison with Alzheimer's, Parkinson's, and Huntington's diseases. Neurology 1994; 44: 1264-70.

8 Fossati P, Harvey PO, Le Bastard G, Ergis AM, Jouvent R, Allilaire JF. Verbal memory performance of patients with a first depressive episode and patients with unipolar and bipolar recurrent depression. J Psychiatr Res 2004; 38: 137-44.

9 Petersen RC, Smith G, Kokmen E, Ivnik RJ, Tangalos EG. Memory function in normal aging. Neurology 1992; 42: 396-401.

10 Sarazin M, Chauvire V, Gerardin E, et al. The amnestic syndrome of hippocampal type in Alzheimer's disease: an MRI study. J Alzheimers Dis 2010; 22: 285-94.

11 Dubois B, Feldman HH, Jacova C, et al. Revising the definition of Alzheimer's disease: a new lexicon. Lancet Neurol 2010; 9: 1118-27.

12 Morris JC, Roe CM, Grant EA, et al. Pittsburgh compound B imaging and prediction of progression from cognitive normality to symptomatic Alzheimer disease. Arch Neurol 2009; 66: 1469-75.

13 Bennett DA, Schneider JA, Arvanitakis Z, et al. Neuropathology of older persons without cognitive impairment from two community-based studies. Neurology 2006; 66: 1837-44.

14 Knopman DS, Parisi JE, Salviati A, et al. Neuropathology of cognitively normal elderly. J Neuropathol Exp Neurol 2003; 62: 1087-95.

15 Jicha GA, Abner EL, Schmitt FA, et al. Preclinical AD Workgroup staging: pathological correlates and potential challenges. Neurobiol Aging 2012; 33: 622 e1-e16.

16 Sperling RA, Aisen PS, Beckett LA, et al. Toward defining the preclinical stages of Alzheimer's disease: recommendations from the National Institute on Aging-Alzheimer's Association workgroups on diagnostic guidelines for Alzheimer's disease. Alzheimers Dement 2011; 7: 280-92.

17 Albert MS, Dekosky ST, Dickson D, et al. The diagnosis of mild cognitive impairment due to Alzheimer's disease: recommendations from the National Institute on AgingAlzheimer's Association workgroups on diagnostic guidelines for Alzheimer's disease. Alzheimers Dement 2011; 7: 270-79.

18 McKhann GM, Knopman DS, Chertkow H, et al. The diagnosis of dementia due to Alzheimer's disease: recommendations from the National Institute on Aging-Alzheimer's Association workgroups on diagnostic guidelines for Alzheimer's disease.

Alzheimers Dement 2011; 7: 263-69.
19 Prestia A, Caroli A, van der Flier WM, et al. Prediction of dementia in MCI patients based on core diagnostic markers for Alzheimer disease. Neurology 2013; 80: 1048-56.

20 Bouwman FH, Verwey NA, Klein M, et al. New research criteria for the diagnosis of Alzheimer's disease applied in a memory clinic population. Dement Geriatr Cogn Disord 2010; 30: 1-7.

21 de Jager CA, Honey TE, Birks J, Wilcock GK. Retrospective evaluation of revised criteria for the diagnosis of Alzheimer's disease using a cohort with post-mortem diagnosis Int J Geriatr Psychiatry 2010; 25: 988-97.

22 Galluzzi S, Geroldi C, Ghidoni R, et al. The new Alzheimer's criteria in a naturalistic series of patients with mild cognitive impairment. J Neurol 2010; 257: 2004-14.

23 Rami L, Sole-Padulles C, Fortea J, et al. Applying the new research diagnostic criteria: MRI findings and neuropsychological correlations of prodromal AD. Int J Geriatr Psychiatry 2012; 27: $127-34$.

24 Frisoni G, Bocchetta M, Chételat G, et al. Imaging markers for Alzheimer's disease: which versus how. Neurology 2013; 81: 487-500.

25 Bateman RJ, Xiong C, Benzinger TL, et al. Clinical and biomarker changes in dominantly inherited Alzheimer's disease. N Engl J Med 2012; 367: 795-804.

26 Reiman EM, Quiroz YT, Fleisher AS, et al. Brain imaging and fluid biomarker analysis in young adults at genetic risk for autosomal dominant Alzheimer's disease in the presenilin 1 E280A kindred: a case-control study. Lancet Neurol 2012; 11: $1048-56$

27 Fleisher AS, Chen K, Quiroz YT, et al. Florbetapir PET analysis of amyloid- $\beta$ deposition in the presenilin 1 E280A autosomal dominant Alzheimer's disease kindred: a cross-sectional study. Lancet Neurol 2012; 11: 1057-65.

28 Birrer RB, Vemuri SP. Depression in later life: a diagnostic and therapeutic challenge. Am Fam Physician 2004; 69: 2375-82.

29 Bronnick K, Alves G, Aarsland D, Tysnes OB, Larsen JP. Verbal memory in drug-naive, newly diagnosed Parkinson's disease. The retrieval deficit hypothesis revisited. Neuropsychology 2011; 25: $114-24$

30 Hornberger M, Piguet O, Graham AJ, Nestor PJ, Hodges JR. How preserved is episodic memory in behavioral variant frontotemporal dementia? Neurology 2010; 74: 472-79.

31 Grober E, Buschke H, Crystal H, Bang S, Dresner R. Screening for dementia by memory testing. Neurology 1988; 38: 900-03.

32 Tounsi H, Deweer B, Ergis AM, et al. Sensitivity to semantic cuing: an index of episodic memory dysfunction in early Alzheimer disease. Alzheimer Dis Assoc Disord 1999; 13: 38-46.

33 Sarazin M, Berr C, De Rotrou J, et al. Amnestic syndrome of the medial temporal type identifies prodromal AD: a longitudinal study. Neurology 2007; 69: 1859-67.

34 Derby CA, Burns LC, Wang C, et al. Screening for predementia AD: time-dependent operating characteristics of episodic memory tests. Neurology 2013; 80: 1307-14.

35 Wagner M, Wolf S, Reischies FM, et al. Biomarker validation of a cued recall memory deficit in prodromal Alzheimer disease. Neurology 2012; 78: 379-86.

36 Fortea J, Sala-Llonch R, Bartres-Faz D, et al. Cognitively preserved subjects with transitional cerebrospinal fluid $\beta$-amyloid 1-42 value have thicker cortex in Alzheimer's disease vulnerable areas. Biol Psychiatry 2011; 70: 183-90.

37 Swerdlow RH, Jicha GA. Alzheimer disease: can the exam predict the pathology? Neurology 2012; 78: 374-75.

38 Dubois B, Touchon J, Portet F, Ousset PJ, Vellas B, Michel B. "The 5 words": a simple and sensitive test for the diagnosis of Alzheimer's disease. Presse Med 2002; 31: 1696-99 (in French).

39 Mura T, Proust-Lima C, Jacqmin-Gadda H, et al. Measuring cognitive change in subjects with prodromal Alzheimer's disease. J Neurol Neurosurg Psychiatry 2014; 85: 363-70.

40 Dierckx E, Engelborghs S, De Raedt R, et al. Verbal cued recall as a predictor of conversion to Alzheimer's disease in Mild Cognitive Impairment. Int J Geriatr Psychiatry 2009; 24: 1094-100.

41 Ahmed S, Mitchell J, Arnold R, Nestor PJ, Hodges JR. Predicting rapid clinical progression in amnestic mild cognitive impairment. Dement Geriatr Cogn Disord 2008; 25: 170-77. 
42 Estevez-Gonzalez A, Kulisevsky J, Boltes A, Otermin P, Garcia-Sanchez C. Rey verbal learning test is a useful tool for differential diagnosis in the preclinical phase of Alzheimer's disease: comparison with mild cognitive impairment and normal aging. Int J Geriatr Psychiatry 2003; 18: 1021-28.

43 Fowler KS, Saling MM, Conway EL, Semple JM, Louis WJ. Paired associate performance in the early detection of DAT. J Int Neuropsychol Soc 2002; 8: 58-71.

44 Landau SM, Harvey D, Madison CM, et al. Comparing predictors of conversion and decline in mild cognitive impairment. Neurology 2010; 75: 230-38.

45 Lowndes GJ, Saling MM, Ames D, Chiu E, Gonzalez LM, Savage GR. Recall and recognition of verbal paired associates in early Alzheimer's disease. J Int Neuropsychol Soc 2008; 14: 591-600.

46 Ricci M, Graef S, Blundo C, Miller LA. Using the Rey Auditory Verbal Learning Test (RAVLT) to differentiate Alzheimer's dementia and behavioural variant fronto-temporal dementia. Clin Neuropsychol 2012; 26: 926-41.

47 Siri S, Benaglio I, Frigerio A, Binetti G, Cappa SF. A brief neuropsychological assessment for the differential diagnosis between frontotemporal dementia and Alzheimer's disease. Eur J Neurol 2001; 8: 125-32.

48 Crane PK, Carle A, Gibbons LE, et al. Development and assessment of a composite score for memory in the Alzheimer's Disease Neuroimaging Initiative (ADNI). Brain Imaging Behav 2012; 6: 502-16.

49 Barbeau E, Didic M, Tramoni E, et al. Evaluation of visual recognition memory in MCI patients. Neurology 2004; 62: 1317-22.

50 Guedj E, Barbeau EJ, Didic M, et al. Identification of subgroups in amnestic mild cognitive impairment. Neurology 2006; 67: 356-58.

51 Bird CM, Chan D, Hartley T, Pijnenburg YA, Rossor MN Burgess N. Topographical short-term memory differentiates Alzheimer's disease from frontotemporal lobar degeneration. Hippocampus 2010; 20: 1154-69.

52 Della Sala S, Parra MA, Fabi K, Luzzi S, Abrahams S. Short-term memory binding is impaired in AD but not in non-AD dementias. Neuropsychologia 2012; 50: 833-40.

53 Parra MA, Abrahams S, Logie RH, Mendez LG, Lopera F, Della Sala S. Visual short-term memory binding deficits in familial Alzheimer's disease. Brain 2010; 133: 2702-13.

54 Blennow K, Hampel H, Weiner M, Zetterberg H. Cerebrospinal fluid and plasma biomarkers in Alzheimer disease. Nat Rev Neurol 2010; 6: 131-44.

55 Buerger K, Ewers M, Pirttila T, et al. CSF phosphorylated tau protein correlates with neocortical neurofibrillary pathology in Alzheimer's disease. Brain 2006; 129: 3035-41.

56 Koopman K, Le Bastard N, Martin JJ, Nagels G, De Deyn PP, Engelborghs S. Improved discrimination of autopsy-confirmed Alzheimer's disease (AD) from non-AD dementias using CSF P-tau(181P). Neurochem Int 2009; 55: 214-18.

57 Seppala TT, Nerg O, Koivisto AM, et al. CSF biomarkers for Alzheimer disease correlate with cortical brain biopsy findings. Neurology 2012; 78: 1568-75.

58 Strozyk D, Blennow K, White LR, Launer LJ. CSF Abeta 42 levels correlate with amyloid-neuropathology in a population-based autopsy study. Neurology 2003; 60: 652-56.

59 Tapiola T, Alafuzoff I, Herukka SK, et al. Cerebrospinal fluid \{beta\}-amyloid 42 and tau proteins as biomarkers of Alzheimer-type pathologic changes in the brain. Arch Neurol 2009; 66: 382-89.

60 Shaw LM, Vanderstichele H, Knapik-Czajka M, et al. Qualification of the analytical and clinical performance of CSF biomarker analyses in ADNI. Acta Neuropathol 2011; 121: 597-609.

61 Le Bastard N, Martin JJ, Vanmechelen E, Vanderstichele H, De Deyn PP, Engelborghs S. Added diagnostic value of CSF biomarkers in differential dementia diagnosis. Neurobiol Aging 2010; 31: 1867-76.

62 Shaw LM, Vanderstichele H, Knapik-Czajka M, et al. Cerebrospinal fluid biomarker signature in Alzheimer's disease neuroimaging initiative subjects. Ann Neurol 2009; 65: 403-13.

63 Blennow K, Hampel H. CSF markers for incipient Alzheimer's disease. Lancet Neurol 2003; 2: 605-13.

64 Slaets S, Le Bastard N, Theuns J, et al. Amyloid pathology influences abeta1-42 cerebrospinal fluid levels in dementia with lewy bodies. J Alzheimers Dis 2013; 35: 137-46.
65 Perret-Liaudet A, Pelpel M, Tholance Y, et al. Risk of Alzheimer's disease biological misdiagnosis linked to cerebrospinal collection tubes. J Alzheimers Dis 2012; 31: 13-20.

66 Mattsson N, Andreasson U, Persson S, et al. CSF biomarker variability in the Alzheimer's Association quality control program. Alzheimers Dement 2013; 9: 251-61.

67 Fagan AM, Roe CM, Xiong C, Mintun MA, Morris JC, Holtzman DM. Cerebrospinal fluid tau/beta-amyloid(42) ratio as a prediction of cognitive decline in nondemented older adults. Arch Neurol 2007; 64: 343-49.

68 Hampel H, Teipel SJ, Fuchsberger T, et al. Value of CSF beta-amyloid1-42 and tau as predictors of Alzheimer's disease in patients with mild cognitive impairment. Mol Psychiatry 2004; 9: 705-10.

69 Hulstaert F, Blennow K, Ivanoiu A, et al. Improved discrimination of AD patients using beta-amyloid(1-42) and tau levels in CSF. Neurology 1999; 52: 1555-62.

70 Ibach B, Binder H, Dragon M, et al. Cerebrospinal fluid tau and beta-amyloid in Alzheimer patients, disease controls and an age-matched random sample. Neurobiol Aging 2006; 27: 1202-11.

71 Smach MA, Charfeddine B, Ben Othman L, et al. Evaluation of cerebrospinal fluid tau/beta-amyloid(42) ratio as diagnostic markers for Alzheimer disease. Eur Neurol 2009; 62: 349-55.

72 Welge V, Fiege O, Lewczuk P, et al. Combined CSF tau, p-tau181 and amyloid-beta 38/40/42 for diagnosing Alzheimer's disease. J Neural Transm 2009; 116: 203-12.

73 Hansson O, Zetterberg H, Buchhave P, Londos E, Blennow K, Minthon L. Association between CSF biomarkers and incipient Alzheimer's disease in patients with mild cognitive impairment: a follow-up study. Lancet Neurol 2006; 5: 228-34.

74 Buchhave P, Minthon L, Zetterberg H, Wallin AK, Blennow K, Hansson O. Cerebrospinal fluid levels of beta-amyloid 1-42, but not of tau, are fully changed already 5 to 10 years before the onset of Alzheimer dementia. Arch Gen Psychiatry 2012; 69: 98-106.

75 Visser PJ, Verhey F, Knol DL, et al. Prevalence and prognostic value of CSF markers of Alzheimer's disease pathology in patients with subjective cognitive impairment or mild cognitive impairment in the DESCRIPA study: a prospective cohort study. Lancet Neurol 2009; 8: 619-27.

76 Mattsson N, Zetterberg H, Hansson O, et al. CSF biomarkers and incipient Alzheimer disease in patients with mild cognitive impairment. JAMA 2009; 302: 385-93.

77 van Rossum IA, Vos S, Handels R, Visser PJ. Biomarkers as predictors for conversion from mild cognitive impairment to Alzheimer-type dementia: implications for trial design. J Alzheimers Dis 2010; 20: 881-91.

78 Ringman JM, Coppola G, Elashoff D, et al. Cerebrospinal fluid biomarkers and proximity to diagnosis in preclinical familial Alzheimer's disease. Dement Geriatr Cogn Disord 2012; 33: 1-5.

79 Ringman JM, Younkin SG, Pratico D, et al. Biochemical markers in persons with preclinical familial Alzheimer disease. Neurology 2008, 71: 85-92.

80 Bian H, Van Swieten JC, Leight S, et al. CSF biomarkers in frontotemporal lobar degeneration with known pathology. Neurology 2008; 70: 1827-35.

81 de Souza LC, Lamari F, Belliard S, et al. Cerebrospinal fluid biomarkers in the differential diagnosis of Alzheimer's disease from other cortical dementias. J Neurol Neurosurg Psychiatry 2011; 82: $240-46$.

82 Schoonenboom NS, Reesink FE, Verwey NA, et al. Cerebrospinal fluid markers for differential dementia diagnosis in a large memory clinic cohort. Neurology 2012; 78: 47-54.

83 Brys M, Pirraglia E, Rich K, et al. Prediction and longitudinal study of CSF biomarkers in mild cognitive impairment. Neurobiol Aging 2009; 30: 682-90.

84 Li G, Sokal I, Quinn JF, et al. CSF tau/Abeta42 ratio for increased risk of mild cognitive impairment: a follow-up study. Neurology 2007; 69: 631-39.

85 Snider BJ, Fagan AM, Roe C, et al. Cerebrospinal fluid biomarkers and rate of cognitive decline in very mild dementia of the Alzheimer type. Arch Neurol 2009; 66: 638-45.

86 Verwey NA, van der Flier WM, Blennow K, et al. A worldwide multicentre comparison of assays for cerebrospinal fluid biomarkers in Alzheimer's disease. Ann Clin Biochem 2009; 46: 235-40. 
87 Fagan AM, Shaw LM, Xiong C, et al. Comparison of analytical platforms for cerebrospinal fluid measures of beta-amyloid 1-42, total tau, and p-tau181 for identifying Alzheimer disease amyloid plaque pathology. Arch Neurol 2011; 68: 1137-44.

88 Carrillo MC, Rowe CC, Szoeke C, et al. Research and standardization in Alzheimer's trials: reaching international consensus. Alzheimers Dement 2013; 9: 160-68.

89 Hort J, Bartos A, Pirttila T, Scheltens P. Use of cerebrospinal fluid biomarkers in diagnosis of dementia across Europe. Eur J Neurol 2010; 17: 90-96.

90 Mattsson N, Andreasson U, Persson S, et al. The Alzheimer's Association external quality control program for cerebrospinal fluid biomarkers. Alzheimers Dement 2011; 7: 386-95 e6.

91 Joshi AD, Pontecorvo MJ, Clark CM, et al. Performance characteristics of amyloid PET with florbetapir F 18 in patients with Alzheimer's disease and cognitively normal subjects. J Nucl Med 2012; 53: 378-84.

92 Rowe CC, Pejoska S, Mulligan RS, et al. Head-to-head comparison of 11C-PiB and 18F-AZD4694 (NAV4694) for beta-amyloid imaging in aging and dementia. J Nucl Med 2013; 54: 880-86.

93 Clark CM, Schneider JA, Bedell BJ, et al. Use of florbetapir-PET for imaging beta-amyloid pathology. JAMA 2011; 305: 275-83.

94 Ikonomovic MD, Klunk WE, Abrahamson EE, et al. Post-mortem correlates of in vivo PiB-PET amyloid imaging in a typical case of Alzheimer's disease. Brain 2008; 131: 1630-45.

95 Leinonen V, Rinne JO, Virtanen KA, et al. Positron emission tomography with [(18) F]flutemetamol and [(11) C]PiB for in vivo detection of cerebral cortical amyloid in normal pressure hydrocephalus patients. Eur J Neurol 2013; 20: 1043-52.

96 Rinne JO, Wong DF, Wolk DA, et al. [(18)F]Flutemetamol PET imaging and cortical biopsy histopathology for fibrillar amyloid beta detection in living subjects with normal pressure hydrocephalus: pooled analysis of four studies. Acta Neuropathol 2012; 124: 833-45.

97 Wolk D, Grachev I, Buckley C, et al. Association between in vivo fluorine 18-labeled flutemetamol amyloid positron emission tomography imaging and in vivo cerebral cortical histopathology. Arch Neurol 2011; 68: 1398-403.

98 Forsberg A, Engler H, Almkvist O, et al. PET imaging of amyloid deposition in patients with mild cognitive impairment. Neurobiol Aging 2008; 29: 1456-65.

99 Jack CR Jr, Knopman DS, Jagust WJ, et al. Hypothetical model of dynamic biomarkers of the Alzheimer's pathological cascade. Lancet Neurol 2010; 9: 119-28.

100 Koivunen J, Scheinin N, Virta JR, et al. Amyloid PET imaging in patients with mild cognitive impairment: a 2-year follow-up study. Neurology 2011; 76: 1085-90.

101 Visser PJ, Knopman DS. Amyloid imaging in the prediction of Alzheimer-type dementia in subjects with amnestic MCI. Neurology 2009; 73: 744-45.

102 Herholz K, Ebmeier K. Clinical amyloid imaging in Alzheimer's disease. Lancet Neurol 2011; 10: 667-70.

103 Aizenstein HJ, Nebes RD, Saxton JA, et al. Frequent amyloid deposition without significant cognitive impairment among the elderly. Arch Neurol 2008; 65: 1509-17.

104 Villemagne VL, Rowe CC. Amyloid imaging. Int Psychogeriatr 2011; 23: $\mathrm{S} 41-49$.

105 Scholl M, Wall A, Thordardottir S, et al. Low PiB PET retention in presence of pathologic CSF biomarkers in Arctic APP mutation carriers. Neurology 2012; 79: 229-36.

106 Cairns NJ, Ikonomovic MD, Benzinger T, et al. Absence of Pittsburgh compound B detection of cerebral amyloid beta in a patient with clinical, cognitive, and cerebrospinal fluid markers of Alzheimer disease: a case report. Arch Neurol 2009; 66: 1557-62.

107 Okello A, Koivunen J, Edison P, et al. Conversion of amyloid positive and negative MCI to AD over 3 years: an 11C-PIB PET study. Neurology 2009; 73: 754-60.

108 Roe CM, Fagan AM, Grant EA, et al. Amyloid imaging and CSF biomarkers in predicting cognitive impairment up to 7.5 years later. Neurology 2013; 80: 1784-91.

109 Fagan AM, Mintun MA, Mach RH, et al. Inverse relation between in vivo amyloid imaging load and cerebrospinal fluid Abeta42 in humans. Ann Neurol 2006; 59: 512-19.
110 Forsberg A, Almkvist O, Engler H, Wall A, Langstrom B, Nordberg A. High PIB retention in Alzheimer's disease is an early event with complex relationship with CSF biomarkers and functional parameters. Curr Alzheimer Res 2010; 7: 56-66.

111 Grimmer T, Riemenschneider M, Forstl H, et al. Beta amyloid in Alzheimer's disease: increased deposition in brain is reflected in reduced concentration in cerebrospinal fluid. Biol Psychiatry 2009; 65: 927-34.

112 Fagan AM, Mintun MA, Shah AR, et al. Cerebrospinal fluid tau and ptau(181) increase with cortical amyloid deposition in cognitively normal individuals: implications for future clinical trials of Alzheimer's disease. EMBO Mol Med 2009; 1: 371-80.

113 Jagust WJ, Landau SM, Shaw LM, et al. Relationships between biomarkers in aging and dementia. Neurology 2009; 73: 1193-99.

114 Tolboom N, van der Flier WM, Yaqub M, et al. Relationship of cerebrospinal fluid markers to 11C-PiB and 18F-FDDNP binding. J Nucl Med 2009; 50: 1464-70.

115 Galton CJ, Patterson K, Xuereb JH, Hodges JR. Atypical and typical presentations of Alzheimer's disease: a clinical, neuropsychological, neuroimaging and pathological study of 13 cases. Brain 2000 123: 484-98.

116 Lopez O, Litvan I, Catt KE, et al. Accuracy of four clinical diagnostic criteria for the diagnosis of neurodegenerative dementias. Neurology 1999; 53: 1292-99.

117 Snowden JS, Stopford CL, Julien CL, et al. Cognitive phenotypes in Alzheimer's disease and genetic risk. Cortex 2007; 43: 835-45.

118 Murray ME, Graff-Radford NR, Ross OA, Petersen RC, Duara R, Dickson DW. Neuropathologically defined subtypes of Alzheimer's disease with distinct clinical characteristics: a retrospective study. Lancet Neurol 2011; 10: 785-96.

119 Crutch SJ, Lehmann M, Schott JM, Rabinovici GD, Rossor MN, Fox NC. Posterior cortical atrophy. Lancet Neurol 2012; 11: 170-78.

120 Warren JD, Fletcher PD, Golden HL. The paradox of syndromic diversity in Alzheimer disease. Nat Rev Neurol 2012; 8: 451-64.

121 Ross SJ, Graham N, Stuart-Green L, et al. Progressive biparietal atrophy: an atypical presentation of Alzheimer's disease. J Neurol Neurosurg Psychiatry 1996; 61: 388-95.

122 Henry ML, Gorno-Tempini ML. The logopenic variant of primary progressive aphasia. Curr Opin Neurol 2010; 23: 633-37.

123 Habek M, Hajnsek S, Zarkovic K, Chudy D, Mubrin Z. Frontal variant of Alzheimer's disease: clinico-CSF-pathological correlation. Can J Neurol Sci 2010; 37: 118-20.

124 Woodward M, Brodaty H, Boundy K, et al. Does executive impairment define a frontal variant of Alzheimer's disease? Int Psychogeriatr 2010; 22: 1280-90.

125 Woodward M, Jacova C, Black SE, et al. Differentiating the frontal variant of Alzheimer's disease. Int J Geriatr Psychiatry 2010; 25: 732-38.

126 Alladi S, Xuereb J, Bak T, et al. Focal cortical presentations of Alzheimer's disease. Brain 2007; 130: 2636-45.

127 Johnson JK, Head E, Kim R, Starr A, Cotman CW. Clinical and pathological evidence for a frontal variant of Alzheimer disease. Arch Neurol 1999; 56: 1233-39.

128 Mendez MF, Joshi A, Tassniyom K, Teng E, Shapira JS Clinicopathologic differences among patients with behaviora variant frontotemporal dementia. Neurology 2013; 80: 561-68.

129 Migliaccio R, Agosta F, Rascovsky K, et al. Clinical syndromes associated with posterior atrophy: early age at onset AD spectrum. Neurology 2009; 73: 1571-78.

130 Snowden JS, Thompson JC, Stopford CL, et al. The clinica diagnosis of early-onset dementias: diagnostic accuracy and clinicopathological relationships. Brain 2011; 134: 2478-92.

131 de Souza LC, Corlier F, Habert MO, et al. Similar amyloid-\{beta\} burden in posterior cortical atrophy and Alzheimer's disease. Brain 2011; 134: 2036-43.

132 Leyton CE, Villemagne VL, Savage S, et al. Subtypes of progressive aphasia: application of the international consensus criteria and validation using \{beta\}-amyloid imaging. Brain 2011; 134: 3030-43.

133 Rosenbloom MH, Alkalay A, Agarwal N, et al. Distinct clinical and metabolic deficits in PCA and AD are not related to amyloid distribution. Neurology 2011; 76: 1789-96

134 Hof PR, Bouras C, Perl DP, Morrison JH. Quantitative neuropathologic analysis of Pick's disease cases: cortical distribution of Pick bodies and coexistence with Alzheimer's disease. Acta Neuropathol 1994; 87: 115-24. 
135 Ball SL, Holland AJ, Watson PC, Huppert FA. Theoretical exploration of the neural bases of behavioural disinhibition, apathy and executive dysfunction in preclinical Alzheimer's disease in people with Down's syndrome: potential involvement of multiple frontal-subcortical neuronal circuits. I Intellect Disabil Res 2010; 54: 320-36.

136 Jellinger KA, Attems J. Prevalence of dementia disorders in the oldest-old: an autopsy study. Acta Neuropathol 2010; 119: 421-33.

137 Schneider JA, Wilson RS, Bienias JL, Evans DA, Bennett DA. Cerebral infarctions and the likelihood of dementia from Alzheimer disease pathology. Neurology 2004; 62: 1148-55.

138 Carotenuto A, Rea R, Colucci L, et al. Late and early onset dementia: what is the role of vascular factors? A retrospective study. J Neurol Sci 2012; 322: 170-75.

139 McKeith IG, Dickson DW, Lowe J, et al. Diagnosis and management of dementia with Lewy bodies: third report of the DLB Consortium. Neurology 2005; 65: 1863-72.

140 McKeith I, O'Brien J, Walker Z, et al. Sensitivity and specificity of dopamine transporter imaging with 123I-FP-CIT SPECT in dementia with Lewy bodies: a phase III, multicentre study. Lancet Neurol 2007; 6: 305-13.

141 Jacova C, Peters KR, Beattie BL, et al. Cognitive impairment no dementia - neuropsychological and neuroimaging characterization of an amnestic subgroup. Dement Geriatr Cogn Disord 2008; 2: 238-47.

142 Johnson DK, Morris JC, Galvin JE. Verbal and visuospatial deficits in dementia with Lewy bodies. Neurology 2005; 65: 1232-38.

143 Kraybill ML, Larson EB, Tsuang DW, et al. Cognitive differences in dementia patients with autopsy-verified AD, Lewy body pathology, or both. Neurology 2005; 64: 2069-73.

144 Kandiah N, Narasimhalu K, Lee J, Chen CL. Differences exist in the cognitive profile of mild Alzheimer's disease and subcortical ischemic vascular dementia. Dement Geriatr Cogn Disord 2009; 27: 399-403.

145 Moorhouse P, Song X, Rockwood K, et al. Executive dysfunction in vascular cognitive impairment in the consortium to investigate vascular impairment of cognition study. J Neurol Sci 2010; 288: 142-46.

146 Blennow K, Hampel H, Zetterberg H. Biomarkers in amyloid-beta immunotherapy trials in Alzheimer's disease. Neuropsychopharmacology 2014; 39: 189-201.

147 Pillai JA, Cummings JL. Clinical trials in predementia stages of Alzheimer disease. Med Clin North Am 2013; 97: 439-57.

148 Bateman RJ, Aisen PS, De Strooper B, et al. Autosomal-dominant Alzheimer's disease: a review and proposal for the prevention of Alzheimer's disease. Alzheimer's Res Ther 2011; 3: 1.

149 Sperling RA, Jack CR Jr., Aisen PS. Testing the right target and right drug at the right stage. Science Transl Med 2011; 3: 111 cm33.

150 Rami L, Sala-Llonch R, Sole-Padulles C, et al. Distinct functional activity of the precuneus and posterior cingulate cortex during encoding in the preclinical stage of Alzheimer's disease. J Alzheimers Dis 2012; 31: 517-26.

151 Harold D, Abraham R, Hollingworth P, et al. Genome-wide association study identifies variants at CLU and PICALM associated with Alzheimer's disease. Nat Genet 2009; 41: 1088-93.

152 Lambert JC, Heath S, Even G, et al. Genome-wide association study identifies variants at CLU and CR1 associated with Alzheimer's disease. Nat Genet 2009; 41: 1094-99.

153 Modrego PJ. Predictors of conversion to dementia of probable Alzheimer type in patients with mild cognitive impairment. Curr Alzheimer Res 2006; 3: 161-70.

154 Jessen F, Amariglio RE, van Boxtel M, et al. A conceptual framework for research on subjective cognitive decline in preclinical Alzheimer's disease. Alzheimers Dement; Accepted.

155 Gallassi R, Oppi F, Poda R, et al. Are subjective cognitive complaints a risk factor for dementia? Neurol Sci 2010; 31: 327-36.

156 Amariglio RE, Becker JA, Carmasin J, et al. Subjective cognitive complaints and amyloid burden in cognitively normal older individuals. Neuropsychologia 2012; 50: 2880-86.

157 Mielke MM, Wiste HJ, Weigand SD, et al. Indicators of amyloid burden in a population-based study of cognitively normal elderly. Neurology 2012; 79: 1570-77.

158 La Joie R, Perrotin A, Barre L, et al. Region-specific hierarchy between atrophy, hypometabolism, and beta-amyloid (Abeta) load in Alzheimer's disease dementia. J Neurosci 2012; 32: 16265-273.
159 Dickerson BC, Wolk DA, Alzheimer's disease neuroimaging I. MRI cortical thickness biomarker predicts AD-like CSF and cognitive decline in normal adults. Neurology 2012; 78: 84-90.

160 Magnin B, Mesrob L, Kinkingnehun S, et al. Support vector machine-based classification of Alzheimer's disease from whole-brain anatomical MRI. Neuroradiology 2009; 51: 73-83.

161 Buckner RL, Sepulcre J, Talukdar T, et al. Cortical hubs revealed by intrinsic functional connectivity: mapping, assessment of stability, and relation to Alzheimer's disease. J Neurosci 2009; 29: 1860-73.

162 Jagust W. Amyloid + activation = Alzheimer's? Neuron 2009; 63: $141-43$.

163 Fayed N, Davila J, Oliveros A, Castillo J, Medrano JJ. Utility of different MR modalities in mild cognitive impairment and its use as a predictor of conversion to probable dementia. Acad Radiol 2008; 15: 1089-98.

164 Kantarci K, Jack CR, Jr. Neuroimaging in Alzheimer disease: an evidence-based review. Neuroimaging Clin N Am 2003; 13: 197-209.

165 Qi Z, Wu X, Wang Z, et al. Impairment and compensation coexist in amnestic MCI default mode network. Neuroimage 2010; 50: $48-55$.

166 Risacher SL, Saykin AJ, West JD, et al. Baseline MRI predictors of conversion from MCI to probable AD in the ADNI cohort. Curr Alzheimer Res 2009; 6: 347-61.

167 Barkhof F, Polvikoski TM, van Straaten EC, et al. The significance of medial temporal lobe atrophy: a postmortem MRI study in the very old. Neurology 2007; 69: 1521-27.

168 Fotuhi M, Do D, Jack C. Modifiable factors that alter the size of the hippocampus with ageing. Nat Rev Neurol 2012; 8: 189-202.

169 de Souza LC, Chupin M, Bertoux M, et al. Is hippocampal volume a good marker to differentiate Alzheimer's disease from frontotemporal dementia? J Alzheimers Dis 2013; 36: 57-66.

170 Frisoni GB, Pievani M, Testa C, et al. The topography of grey matter involvement in early and late onset Alzheimer's disease. Brain 2007 130: $720-30$.

171 Whitwell JL, Dickson DW, Murray ME, et al. Neuroimaging correlates of pathologically defined subtypes of Alzheimer's disease: a case-control study. Lancet Neurol 2012; 11: 868-77.

172 Giedd JN, Kozuch P, Kaysen D, et al. Reliability of cerebral measures in repeated examinations with magnetic resonance imaging. Psychiatry Res 1995; 61: 113-19.

173 den Heijer T, van der Lijn F, Koudstaal PJ, et al. A 10-year follow-up of hippocampal volume on magnetic resonance imaging in early dementia and cognitive decline. Brain 2010; 133: 1163-72.

174 Lo RY, Hubbard AE, Shaw LM, et al. Longitudinal change of biomarkers in cognitive decline. Arch Neurol 2011; 68: 1257-66.

175 Anchisi D, Borroni B, Franceschi M, et al. Heterogeneity of brain glucose metabolism in mild cognitive impairment and clinical progression to Alzheimer disease. Arch Neurol 2005; 62: 1728-33.

176 Drzezga A, Lautenschlager N, Siebner H, et al. Cerebral metabolic changes accompanying conversion of mild cognitive impairment into Alzheimer's disease: a PET follow-up study. Eur J Nucl Med Mol Imaging 2003; 30: 1104-13.

177 Mosconi L. Brain glucose metabolism in the early and specific diagnosis of Alzheimer's disease. FDG-PET studies in MCI and AD. Eur J Nucl Med Mol Imaging 2005; 32: 486-510.

178 Alexander GE, Chen K, Pietrini P, Rapoport SI, Reiman EM. Longitudinal PET evaluation of cerebral metabolic decline in dementia: a potential outcome measure in Alzheimer's disease treatment studies. Am J Psychiatry 2002; 159: 738-45.

179 de Leon MJ, Convit A, Wolf OT, et al. Prediction of cognitive decline in normal elderly subjects with 2-[(18)F]fluoro-2-deoxy-D-glucose/ poitron-emission tomography (FDG/PET). Proc Natl Acad Sci USA 2001; 98: 10966-71.

180 Johnson KA, Fox NC, Sperling RA, Klunk WE. Brain imaging in Alzheimer disease. Cold Spring Harb Perspect Med 2012; 2: a006213.

181 Mosconi L, Mistur R, Switalski R, et al. FDG-PET changes in brain glucose metabolism from normal cognition to pathologically verified Alzheimer's disease. Eur J Nucl Med Mol Imaging 2009; 36: 811-22.

182 Caroli A, Prestia A, Chen K, et al. Summary metrics to assess Alzheimer disease-related hypometabolic pattern with 18F-FDG PET: head-to-head comparison. J Nucl Med 2012; 53: 592-600. 
183 Scholl M, Almkvist O, Bogdanovic N, et al. Time course of glucose metabolism in relation to cognitive performance and postmortem neuropathology in Met146Val PSEN1 mutation carriers. J Alzheimers Dis 2011; 24: 495-506.

184 Giovacchini G, Squitieri F, Esmaeilzadeh M, Milano A, Mansi L Ciarmiello A. PET translates neurophysiology into images: A review to stimulate a network between neuroimaging and basic research. J Cell Physiol 2011; 226: 948-61.

185 Rocher AB, Chapon F, Blaizot X, Baron JC, Chavoix C. Resting-state brain glucose utilization as measured by PET is directly related to regional synaptophysin levels: a study in baboons. Neuroimage 2003; 20: 1894-98.

186 Bohnen NI, Djang DS, Herholz K, Anzai Y, Minoshima S Effectiveness and safety of 18F-FDG PET in the evaluation of dementia: a review of the recent literature. J Nucl Med 2012 53: 59-71.

187 Lehmann M, Ghosh PM, Madison C, et al. Diverging patterns of amyloid deposition and hypometabolism in clinical variants of probable Alzheimer's disease. Brain 2013; 136: 844-58.

188 Silverman DH, Truong CT, Kim SK, et al. Prognostic value of regional cerebral metabolism in patients undergoing dementia evaluation: comparison to a quantifying parameter of subsequen cognitive performance and to prognostic assessment without PET. Mol Genet Metab 2003; 80: 350-55.

189 Kennedy AM, Frackowiak RS, Newman SK, et al. Deficits in cerebral glucose metabolism demonstrated by positron emission tomography in individuals at risk of familial Alzheimer's disease. Neurosci Lett 1995; 186: 17-20.

190 Reiman EM, Chen K, Alexander GE, et al. Functional brain abnormalities in young adults at genetic risk for late-onset Alzheimer's dementia. Proc Natl Acad Sci USA 2004; 101: 284-89.

191 Small GW, Ercoli LM, Silverman DH, et al. Cerebral metabolic and cognitive decline in persons at genetic risk for Alzheimer's disease. Proc Natl Acad Sci USA 2000; 97: 6037-42.

192 Foster NL, Heidebrink JL, Clark CM, et al. FDG-PET improves accuracy in distinguishing frontotemporal dementia and Alzheimer's disease. Brain 2007; 130: 2616-35.

193 Mosconi L, Tsui WH, Herholz K, et al. Multicenter standardized 18F-FDG PET diagnosis of mild cognitive impairment, Alzheimer's disease, and other dementias. J Nucl Med 2008; 49: 390-98.

194 Rabinovici GD, Jagust WJ, Furst AJ, et al. Abeta amyloid and glucose metabolism in three variants of primary progressive aphasia. Ann Neurol 2008; 64: 388-401.

195 Ewers M, Insel PS, Stern Y, Weiner MW, Alzheimer's Disease Neuroimaging Initiative. Cognitive reserve associated with FDGPET in preclinical Alzheimer disease. Neurology 2013; 80: 1194-201.

196 Garibotto V, Borroni B, Kalbe E, et al. Education and occupation as proxies for reserve in aMCI converters and AD: FDG-PET evidence. Neurology 2008; 71: 1342-49.
197 Stern Y. Cognitive reserve in ageing and Alzheimer's disease. Lancet Neurol 2012; 11: 1006-12.

198 Isaac M, Vamvakas S, Abadie E, Jonsson B, Gispen C, Pani L. Qualification opinion of novel methodologies in the predementia stage of Alzheimer's disease: cerebro-spinal-fluid related biomarkers for drugs affecting amyloid burden - regulatory considerations by European Medicines Agency focusing in improving benefit/risk in regulatory trials. Eur Neuropsychopharmacol 2011; 21: 781-88.

199 Lowe VJ, Peller PJ, Weigand SD, et al. Application of the Nationa Institute on Aging-Alzheimer's Association AD criteria to ADNI. Neurology 2013; 80: 2130-37.

200 Stricker NH, Chang YL, Fennema-Notestine C, et al. Distinct profiles of brain and cognitive changes in the very old with Alzheimer disease. Neurology 2011; 77: 713-21.

201 Butters MA, Lopez OL, Becker JT. Focal temporal lobe dysfunction in probable Alzheimer's disease predicts a slow rate of cognitive decline. Neurology 1996; 46: 687-92.

202 Cappa A, Calcagni ML, Villa G, et al. Brain perfusion abnormalities in Alzheimer's disease: comparison between patients with focal temporal lobe dysfunction and patients with diffuse cognitive impairment. J Neurol Neurosurg Psychiatry 2001; 70: 22-27.

203 Marra C, Villa G, Quaranta D, Valenza A, Vita MG, Gainotti G. Probable Alzheimer's disease patients presenting as "focal temporal lobe dysfunction" show a slow rate of cognitive decline. $J$ Int Neuropsychol Soc 2012; 18: 144-50.

204 Mattsson N, Rosen E, Hansson O, et al. Age and diagnostic performance of Alzheimer disease CSF biomarkers. Neurology 2012 78: $468-76$.

205 Savva GM, Wharton SB, Ince PG, et al. Age, neuropathology, and dementia. N Engl J Med 2009; 360: 2302-09.

206 Holland D, Desikan RS, Dale AM, McEvoy LK, Alzheimer's Disease Neuroimaging Initiative. Rates of decline in Alzheimer disease decrease with age. PLoS One 2012; 7: e42325.

207 Dartigues JF, Feart C. Risk factors for Alzheimer disease: aging beyond age? Neurology 2011; 77: 206-07.

208 Chiu HF, Lam LC. Relevance of outcome measures in different cultural groups--does one size fit all? Int Psychogeriatr 2007; 19: 457-66.

209 Caramelli P, Barbosa MT, Sakurai E, et al. The Pieta study: epidemiological investigation on successful brain aging in Caete (MG), Brazil. Methods and baseline cohort characteristics. Arq Neuropsiquiatr 2011; 69: 579-84.

210 Karlawish J. Addressing the ethical, policy, and social challenges of preclinical Alzheimer disease. Neurology 2011; 77: 1487-93.

211 Antoine P, Pasquier F. Emotional and psychological implications of early AD diagnosis. Med Clin North Am 2013; 97: 459-75. 